\title{
التمكين كإستراتيجية لتنمية الرأسمال الفكري بالمنظمات
}

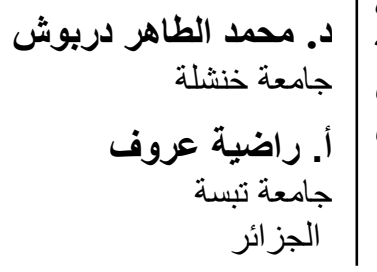

\begin{abstract}
Was thought until recently time مقدمة that wealth which consists of tangible assets such as land and

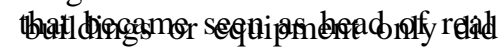
momedhitk anf etrenitiapapillor fae themenntinuationeand astivity the thomprosinization, whealithht Bit the

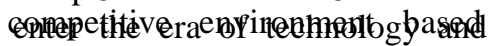

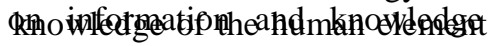

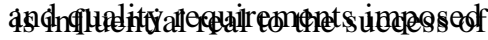

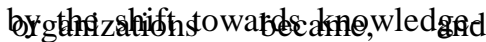

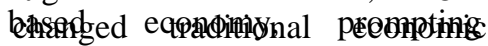
argindiptsionsd began to imange attentiebnothic thenceprackesed of inholletuge of inteneitalal assend knowledge underlying the dimensions and its role in value creation, within this framework, 2015. discuss the analysis and through this paper empowerment a strategy for the development of intellectual capital.

Keywords: intellectual capital, intellectual capital development, empowerment, empowerment strategy.
\end{abstract}


تتفوق بها على المنافسين وترقى إلى المستوى

تمتلك المؤسسة العديد من الموارد التي

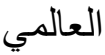

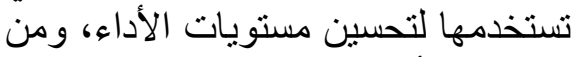

تم تحقيق أهدافها, لكن في ظل تصنات تصاعد

ثورة الحاسوب و أهمية المعلومات فئ تعاظم

دور المعرفة كوحدة إنسانية للثروة التعافة

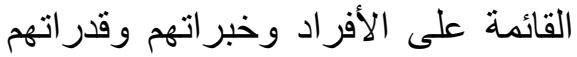

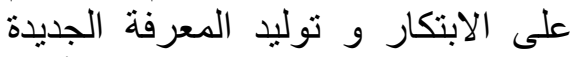

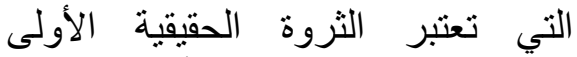

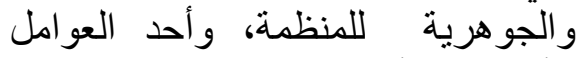

الأساسية للأداء، حيث تسمح للمؤسسة

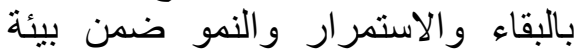

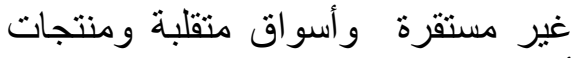

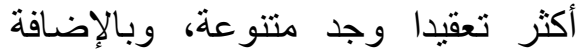

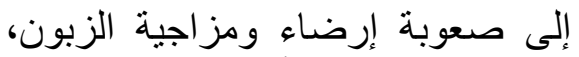

وتحقق المستوى الأعلى من الكفاءة و ولنه

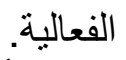

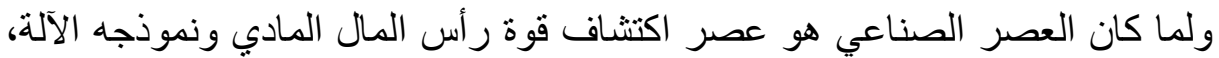

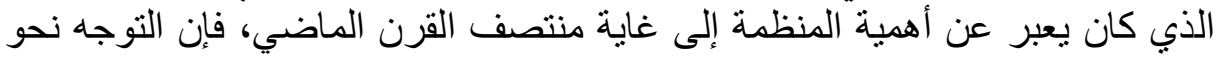

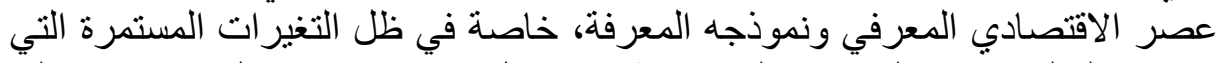

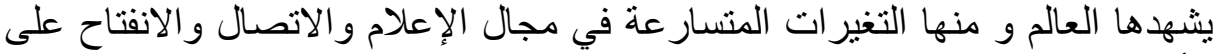

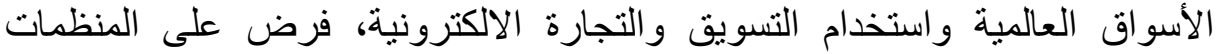

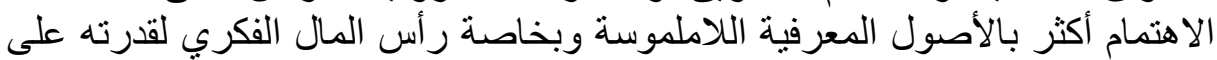

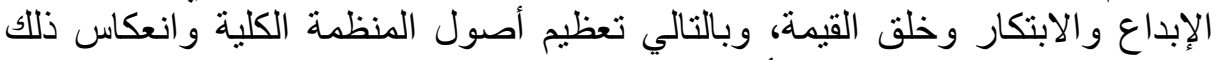

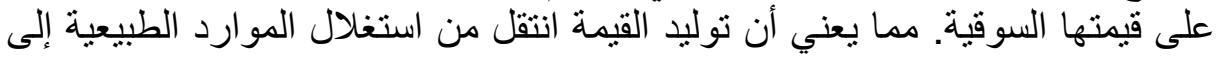

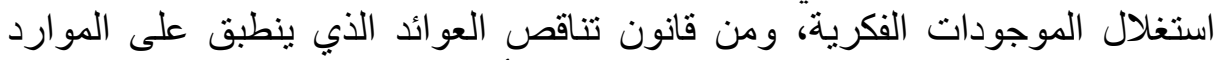

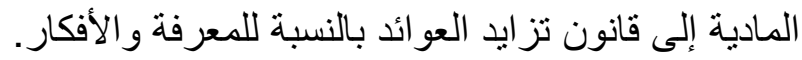

ومن هنا استحوذ رأس المال الفكري من قبل منظمات الأعمال الر اغبة في التفوق

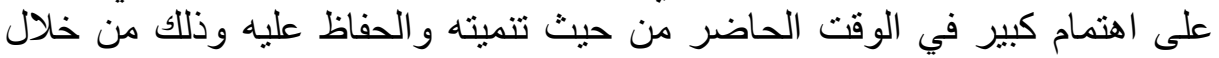

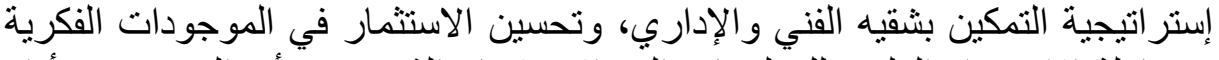

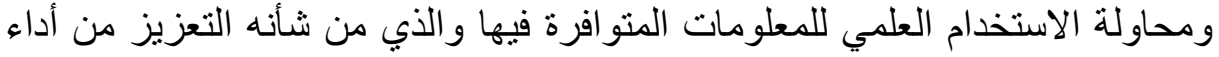

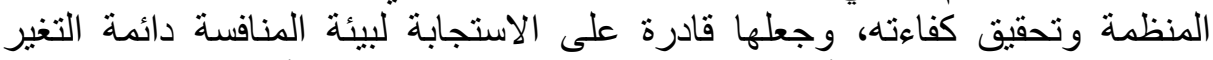

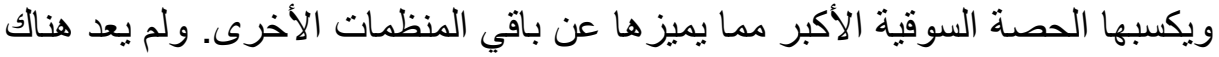


أدنى شك أن كل منظمة ناجحة اليوم تمتلك حزمة و اسعة من اللاملموسات التي تمثل جوهر ها.

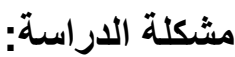

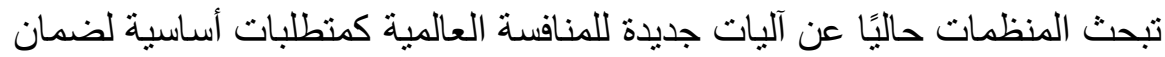

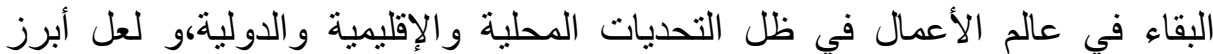

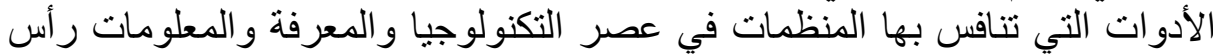

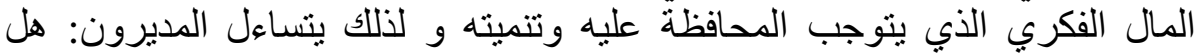
التمكين إستراتيجية فعالة لتنمية الر أسمال الفكري؟ والب وتئه و هو التساؤل الذي ترتكز عليه مشكلة در اسة في هذه الورقة البحثية.

\section{أهـية البحث}

تدعو الضرورة في البداية إلى الإحاطة بالأهمية العلمية، و الفائدة العملية من القيام

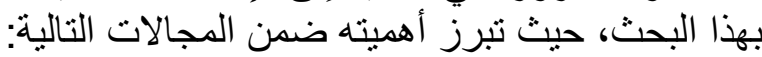

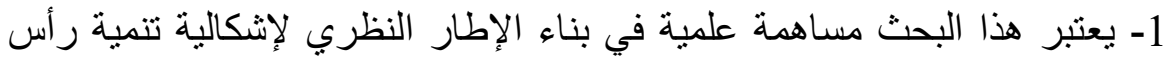

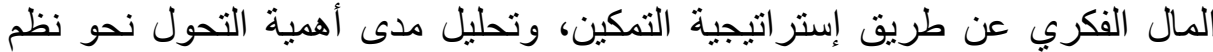
تسيير رأس المال الفكري في ظل الإنتصاد المعرفي.

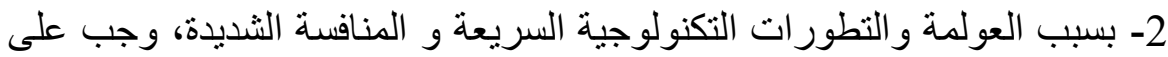

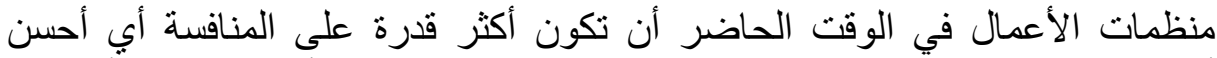

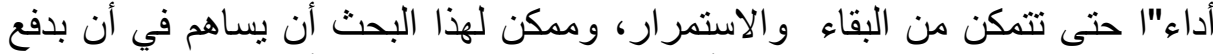

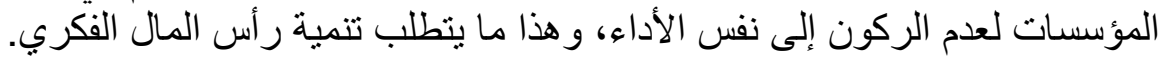

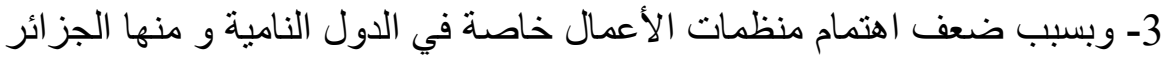

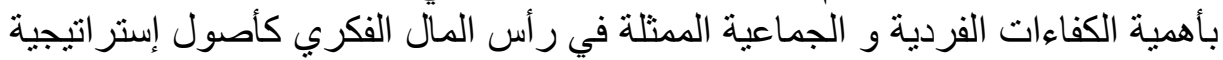
تحقق التميز، يمكن لهذا البحث أن يساهم في زيادة تحسيس مسيري الكئه المنظمات بأهمية هاته الأصول ذات المهار ات و القدرات التهن المتميزة. المحور الأول: إستراتيجية التمكين بين المفهوم و التطبيق

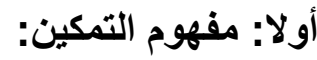

لقد تعددت تعاريف تمكين العاملين وفقا لاتجاهات الكتاب، من ضمنها يمكن

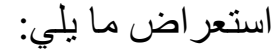
"هو إجر اء يؤدي إلى توطيد ثقة الفرد بقدر اته الذاتية، وقدرته على اتخاذ القرارات

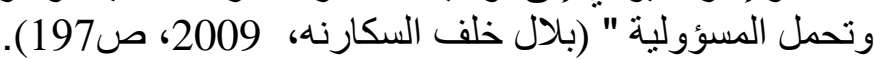

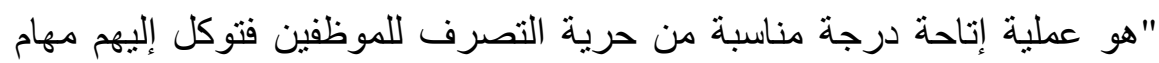
يؤدونها بدرجة من الاستقلالية من مسؤولياتهم عن النتائج، معززين بنظة بنام فاعل 
للمعلومات يهيئ تدفقا سريعا لها مع التركيز في ذللك على العاملين الذين يمارسون

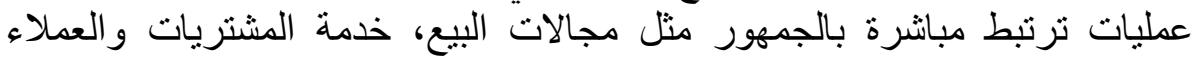

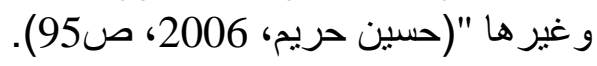

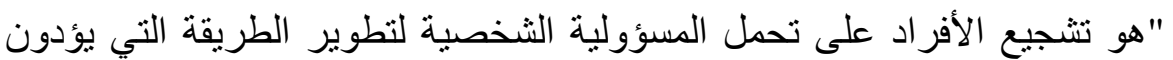

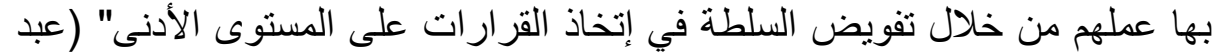

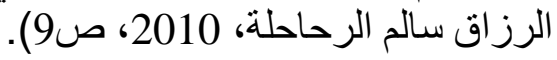

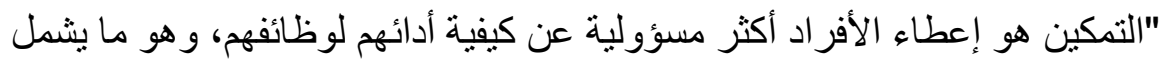

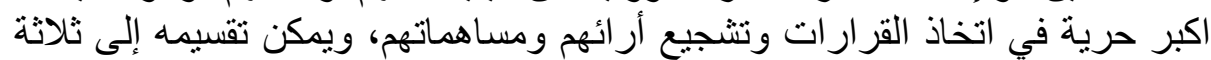

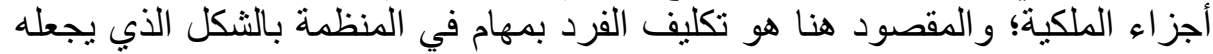

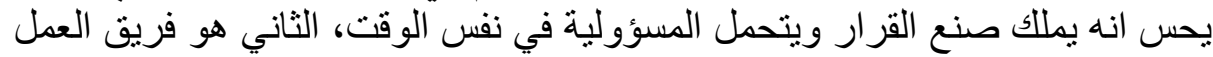

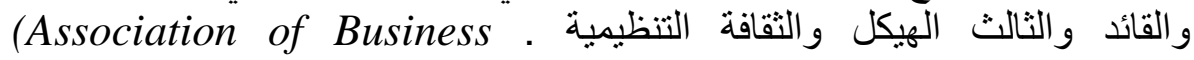
Executives, without edition year, p105)

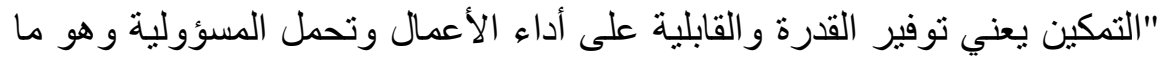

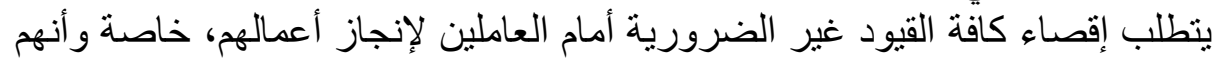

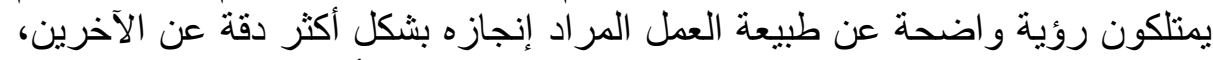

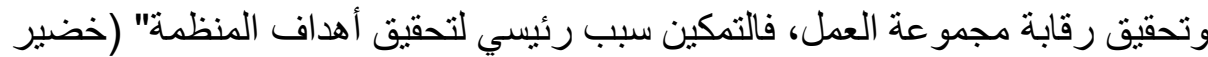

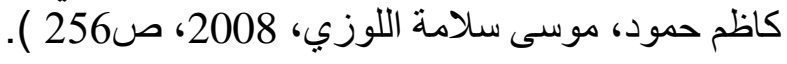

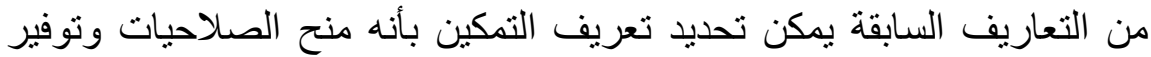

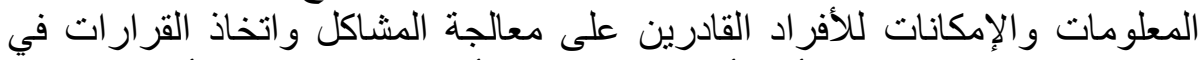

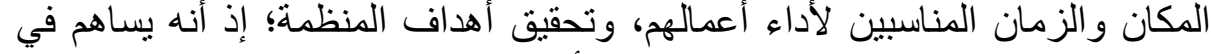

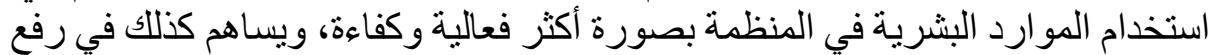

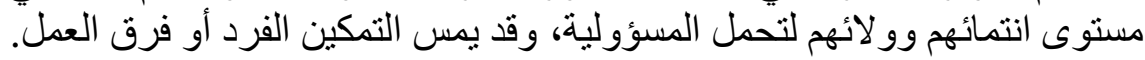

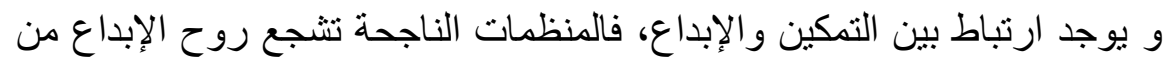

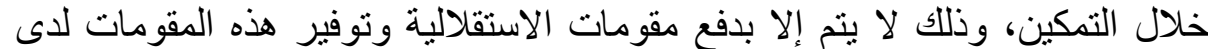

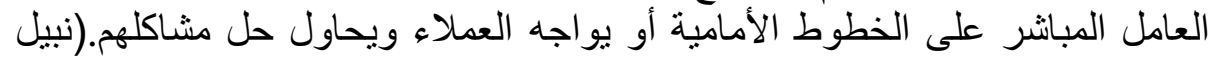

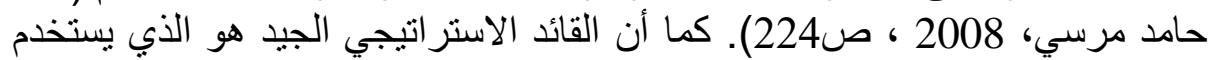

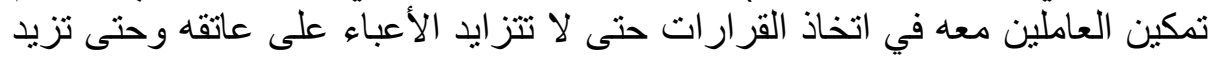

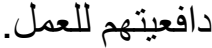

ثنانيا: أسباب تمكين العاملين: Workers Empowerment Causes

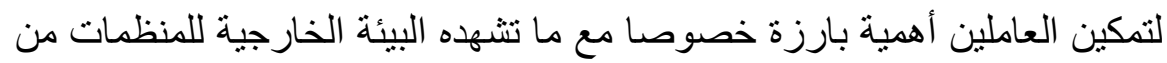

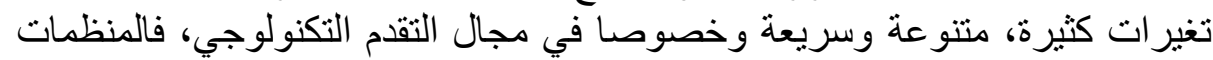

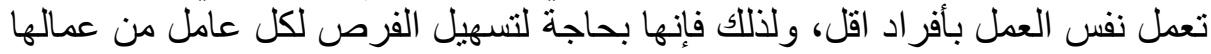

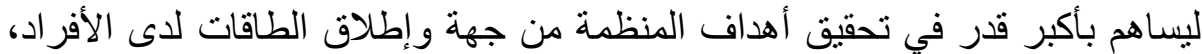




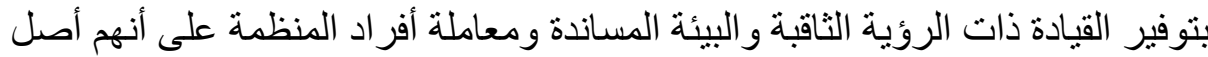

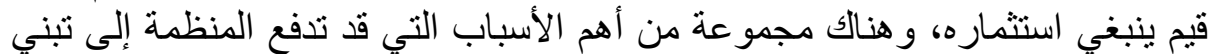

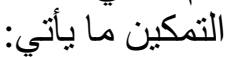
- حاجة المنظمة إلى أن تكون أكثر استجابة للسوق، وتخفيض عدد المستويات

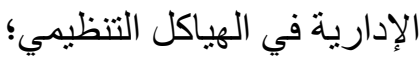
ـ الحاجة إلى عدم انشغال الإدارة العليا بالأمور اليومية وتركيز ها على القضايا الإستر اتيجية طويلة الأجل؛ الإن النغال ـ الحاجة إلى الاستغلال الأمثل لجميع الموارد المتاحة، خاصة الموارد البشرية،

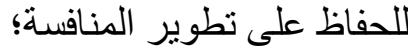
ـ أهمية سر عة اتخاذ القرار اته، وإطلاق القدرات الإبداعية للأفر اد؛

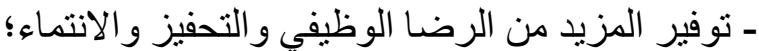
ـ الحد من تكاليف التشغيل؛ بالتقليل من عدد المستويات الإدارية غير الضرورية ووظائف الأفر اد؛ - إعطاء الأفراد مسؤولية اكبر وتمكينهم من اكتساب إحساس اكبر بالانجاز في

Empowerment Steps : تالثا: مراحل التمكين تمر عملية التمكين بعدة مراحل يمكن ذكر ها في ما يلي: (زكريا مطلك الدوري،

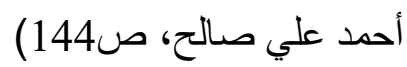
1- مرحلة التهيئة المبدئية:

وذللك بتهيئة البيئة المنظمية الداعمة للتمكين، وإزالة العوائق التي تحول دون

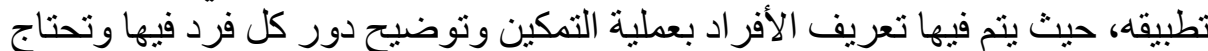
هذه المرحلة إلى قيادة قوية، ودراية واسعة بعملية التمكين للإجابة عن الأسئلة التي

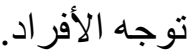

\section{2- مرحلة وضع الأهداف وجدولتهازمنيا:}

تحتاج هذه المرحلة إلى القائد الذي يمارس دور المنسق؛ الذي يستمع للجميع ويقوم

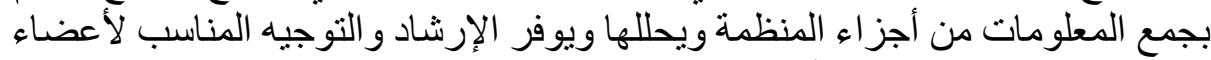

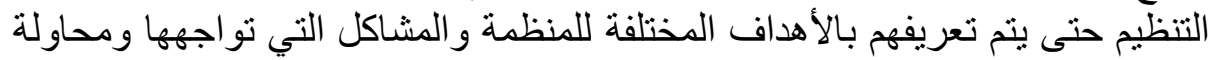

3- مرحلة التسـيلات المادية في بيئة العمل:

تتضمن توفير التسهيلات المالية والمادية الكافية التي تساعد على تجسيد تمكين

العاملين في المنظمة بأفضل شكل.

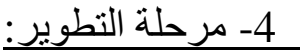


يتم خلال هذه المرحلة اعتماد آليات التطبيق، التقويم، والضبط و التطوير بحيث

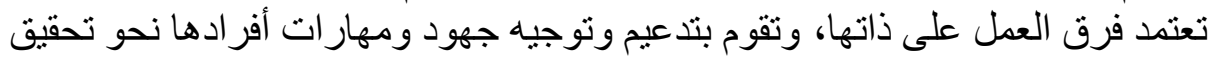

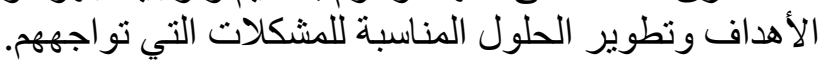

\section{رابعا: مستويات التمكين Empowerment Levels}

تسعى المنظمات من خلال تمكين العاملين فيها لإيجاد مستوى جديد داخلهات الماتها،

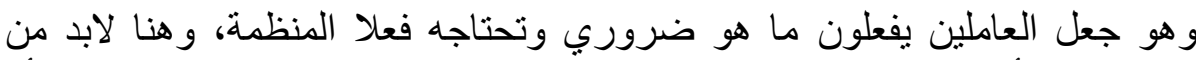

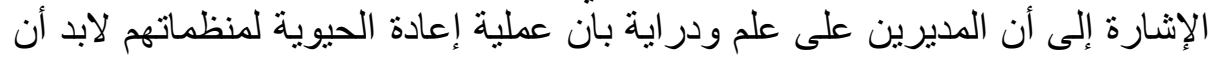

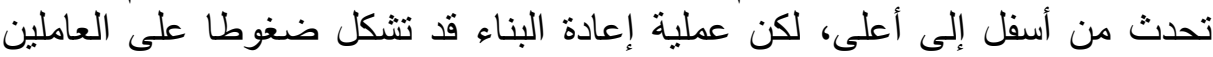

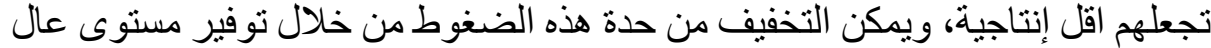
من الانفتاح لدى الإدارة العليا.

ينقسم تمكين العاملين إلى ثلاث مستويات تعكس درجة السلطة التي التي يمارسها

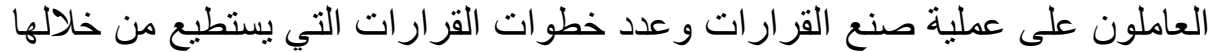

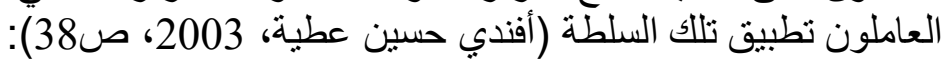

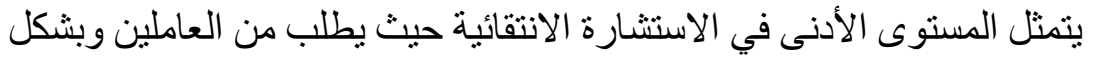

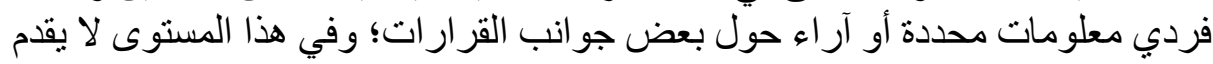
العاملون الحلول وقد لا يعرفون تفاصيل المشكلة التي تستخدم من اجلها المعلومات التهات.

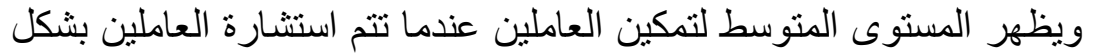

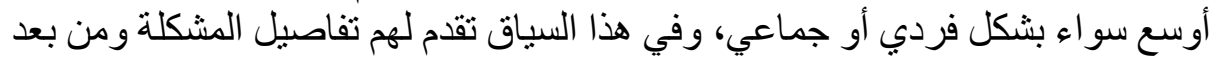

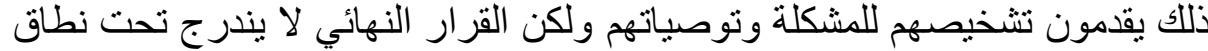

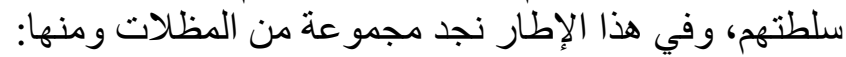
ل

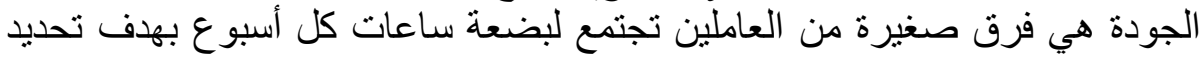

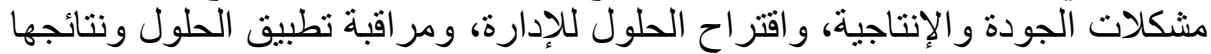

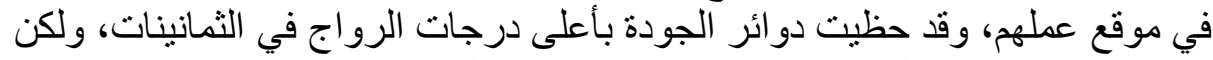

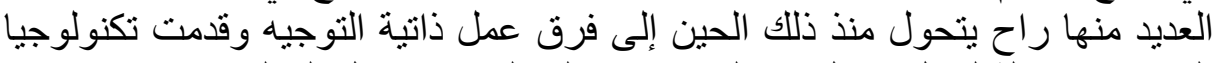

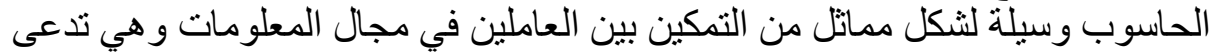

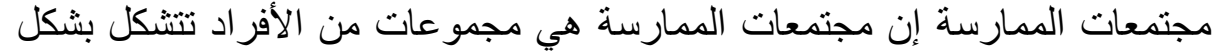

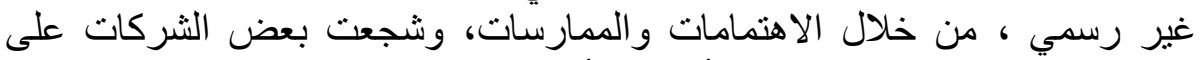
تشكيل مثل هذه الفرق الافتر اضية أملا في أن تسهم في تقديم طرق لتحني لتحين ممارسات

وتتدرج برامج اقتسام المكاسب Gain Sharing ضدن المستوى المتوسط

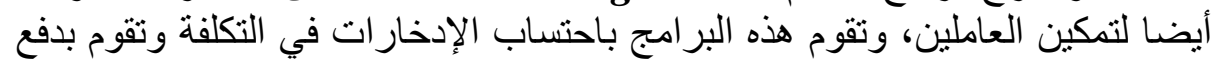
المكافأة ذاتها لجميع أعضاء العرين ونفئ من خلال احتساب صيغة محددة سلفا، ويعتبر 
تمكين العاملين عنصر ا أساسيا في نجاح برامج اقتسام المكاسب وذللك لان إدخارات التكلفة تنتج عن الأفكار التي يقدمها العاملون.

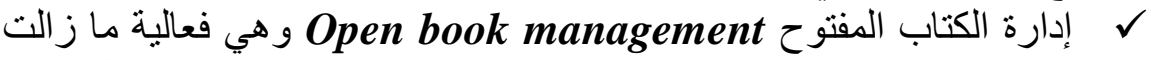

تحظى برواج منزايد وتتطلب تمكين العاملين من المستوى المتوسط، وتتنتمل إدارة

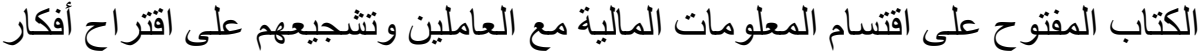
من شأنها أن تحسن هذه النتائج المالية، و غالبا ما يكون ذلاتك مرتبطا بخطة لالقتسام المكاسب أو توزيع الأسهر على العهن العاملين.

يظهر المستوى الأعلى لتمكين العاملين عندما يتسم العاملين بالمشاركة العالين العالية

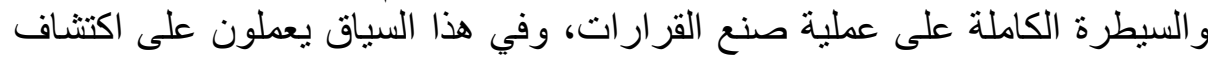

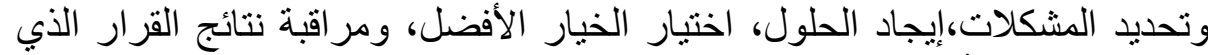
يتخذونه، وتعتبر أبعاد التمكين العالية هذه من خصائص المنظمات التيات المستندة إلى الفرق.

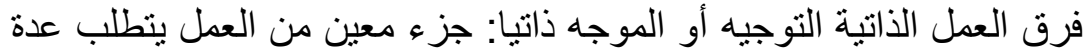

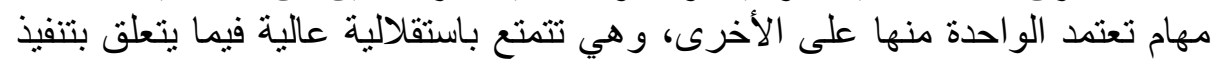

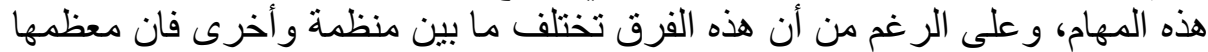

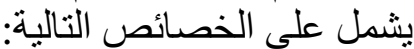
ل أو لا: أن الفريق بكمل جزءا كاملا من العمل سواء كان ذلك منتجا، خدمة، أم

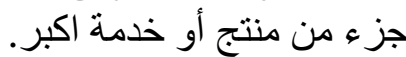
ل كانيا: إن المهام التي يقوم بأدائها أعضاء الفريق يتم تحديدها من قبل الفريق

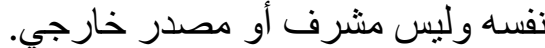
ثالثا: يسيطر الفريق على معظم مدخلات وتدفقات ومخرجات العمل.

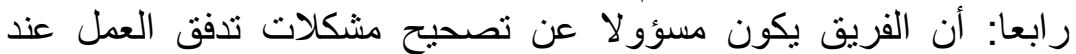

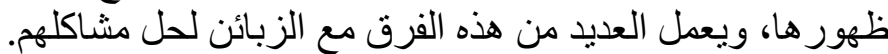

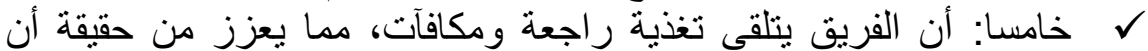

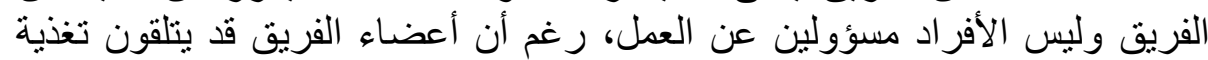
راجعة ومكافآت على المستوى الفردي.

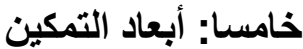
يتأثر التمكين بطرفي معادلة: الطرف الأول وهو البعد الإداري الذي يتيح له حرية

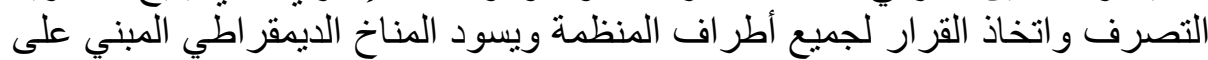

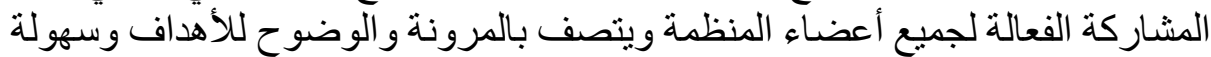

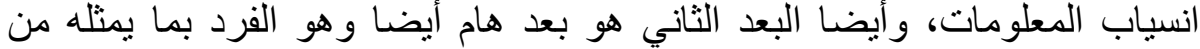

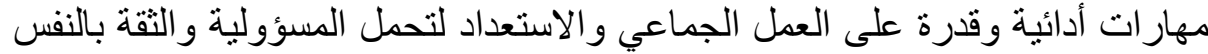

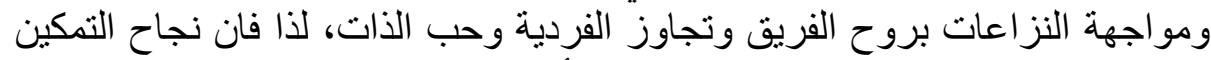

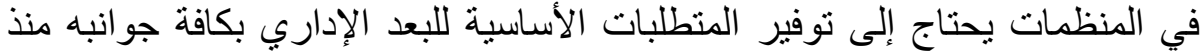

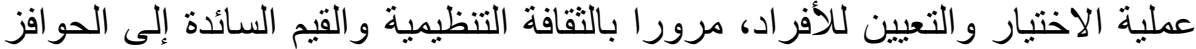

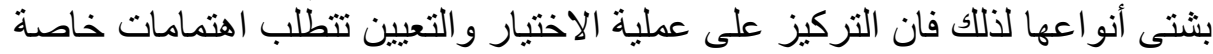


كونها هي الرافد الرئيسي للأفر اد العاملين، وبعد ذلك يتطلب أكثر تصميم البرامج

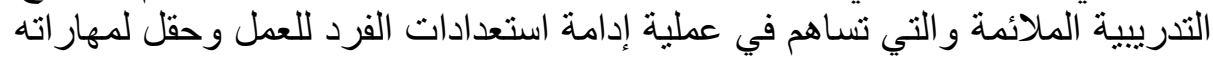

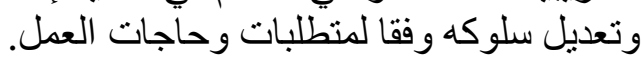
في ما يلي سيتم التعرض لأبعاد التمكين: *حرية الاختيار:

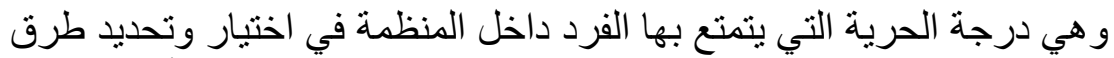

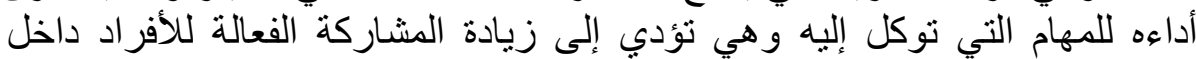

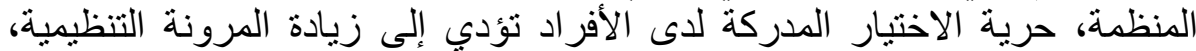

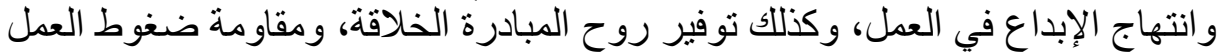

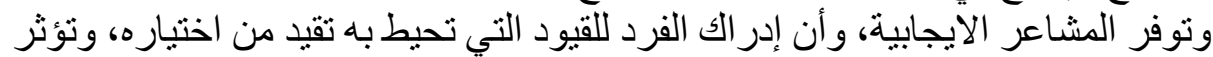

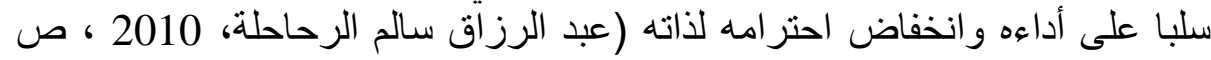

إن بعد حرية الاختيار من الأبعاد الهامة في تفسير مفهوم التمكين ولتأثنيره المحفز الأنيا

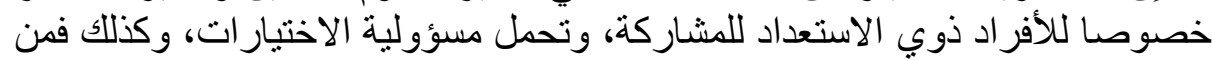

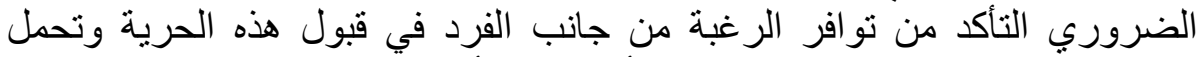

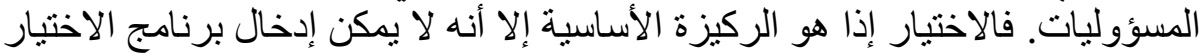

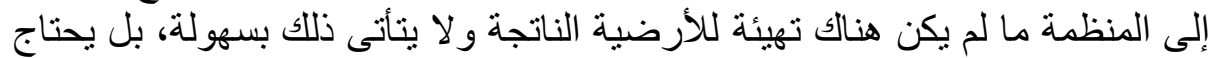

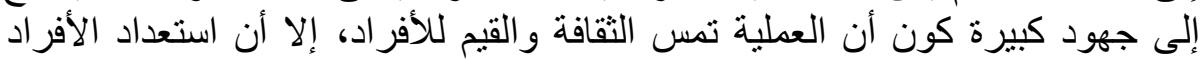

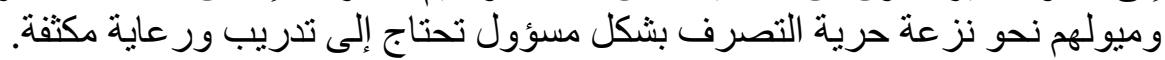

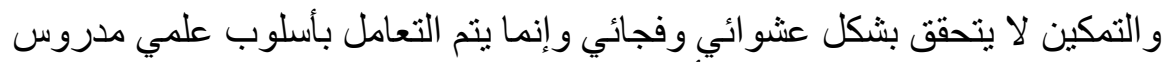

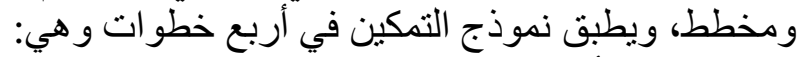
- ت تهيئة الأرضية المناسبة للتمكين.

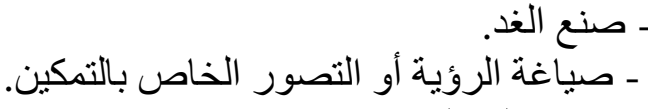
ـ ت تنفيذ عملية التغيير.

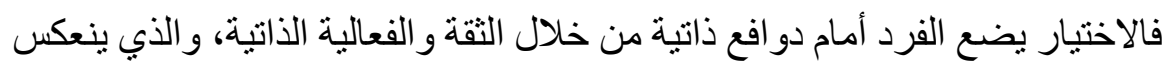

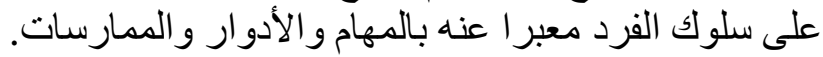

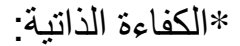

و هي القدرات التي يملكها الفرد ويستخدمها في الظروف المختلفة بغية تحقيق

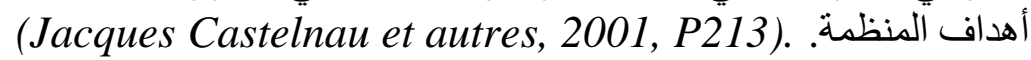

كذلك هي قدرة الفرد على أداء و إنجاز المهام الموكلة إليه بكفاءة و اقتدار نتيجة

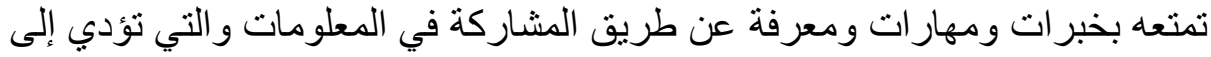


بناء التقة بين الإدارة و الأفر اد وتجعلهم على معرفة بالأحداث و التغير ات المحيطة بهم التهات و الوضع الذي توجد عليه المنظمة ولابد من أن تكون المعلومات سليمة وصحيحة

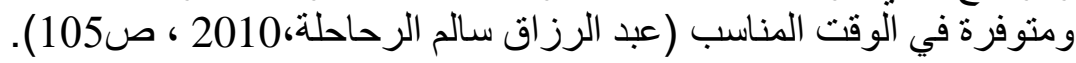

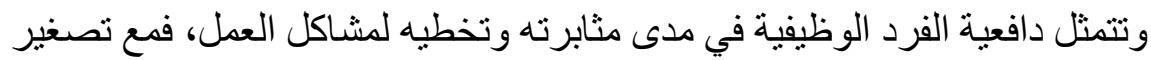

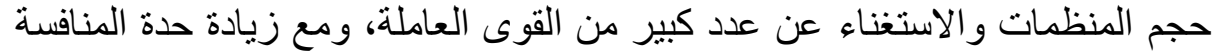

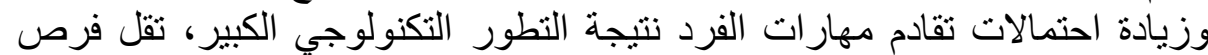

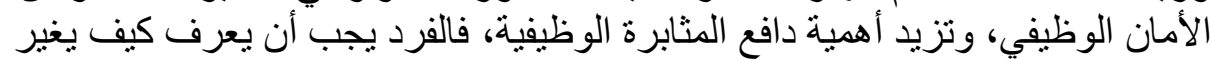

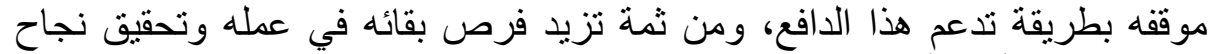

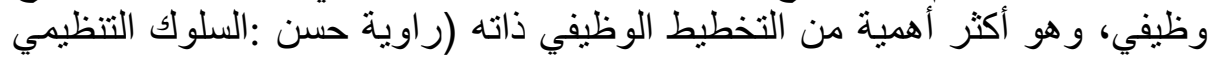

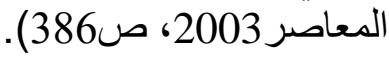
ومن أسباب كفاءة الفرد: اكتسابه للقدر ات و المهار ات و والمعارف وقات وقدرته على التغلب

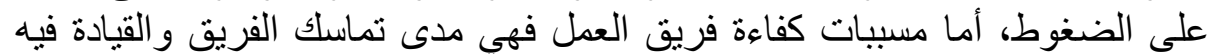
و الأدوار التي يقوم بهاو غير ها (نعمة عباس الخفاجي، طاهر محسن الغالبي، 2010 ،

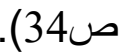

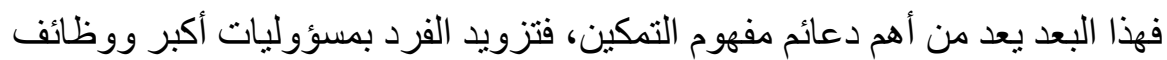

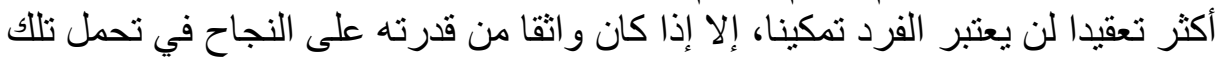

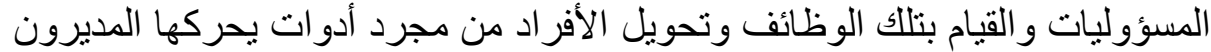

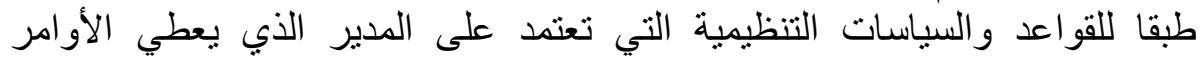

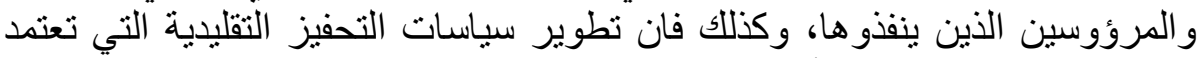

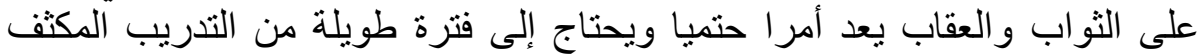

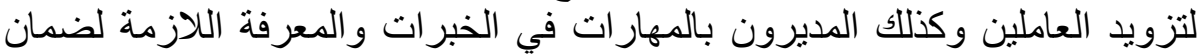

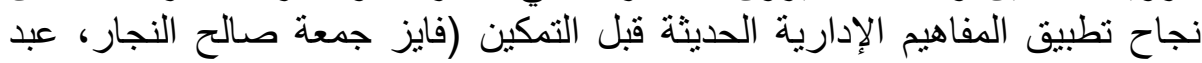

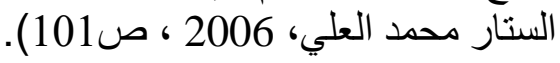

$$
\text { :معنى العمل: }
$$

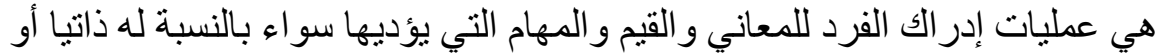

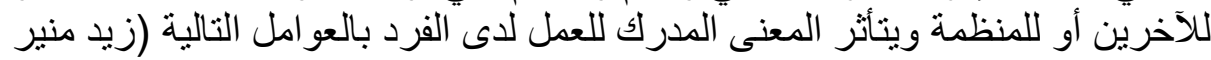

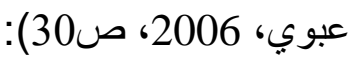

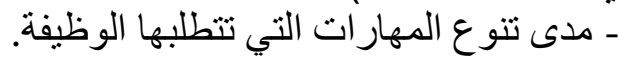

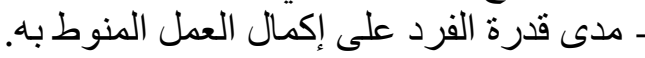
ـ الأهمية النسبية للوظيفة.

ويعتمد إدراك معنى العمل على الأهمية التي تتمتع بها الوظيفة التي يشغلها الفئه الفرد

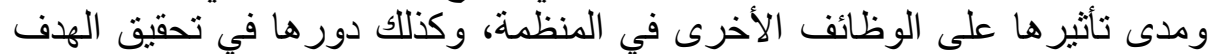

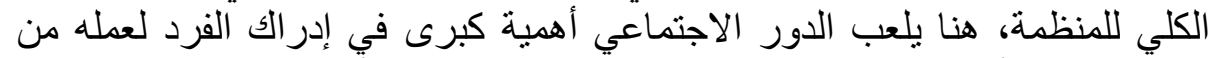

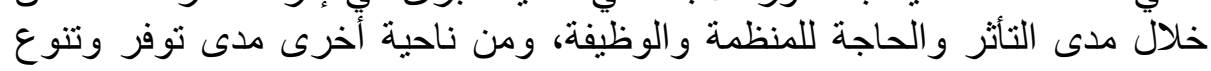




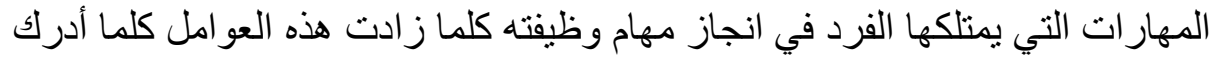

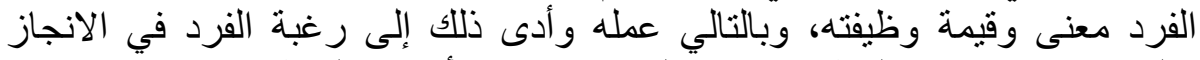
و المشاركة مما يثري الوظيفة وينجح الفرد في تحقيق أهداف المنظمة ولئ.

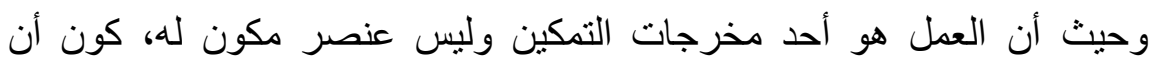

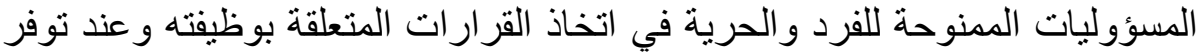

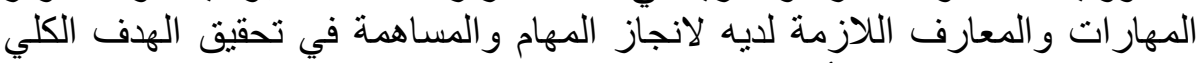
للمنظمة فانه يشعر بذاته و أهميته.

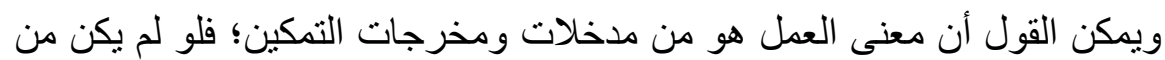

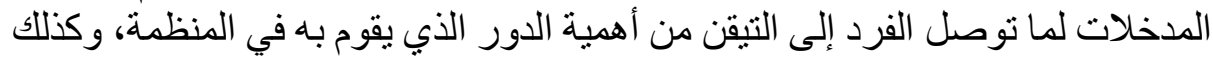

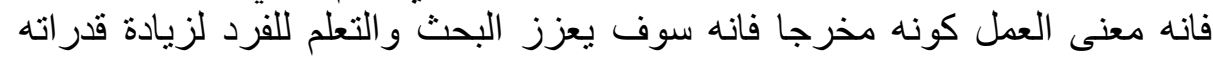
ومهار اته للحصول على أهمية مضافة إلى ما يتحلى بهان. : التأثنر:

و هو تيقن وإدراك الفرد واعتقاده بان لله تأثير على القرارات التي يتم اتخاذها تئها

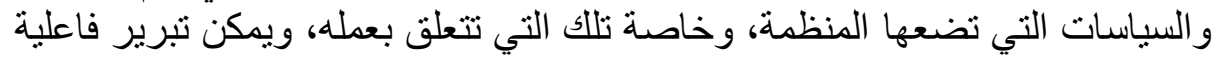

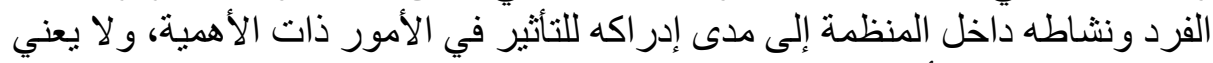

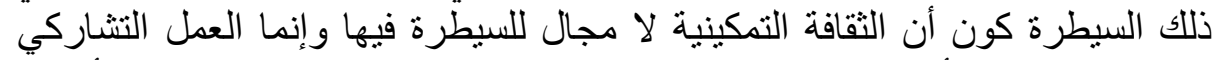

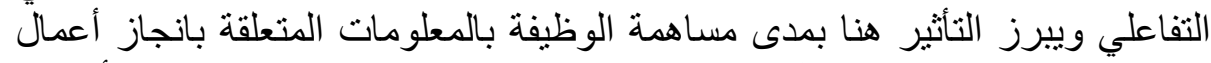

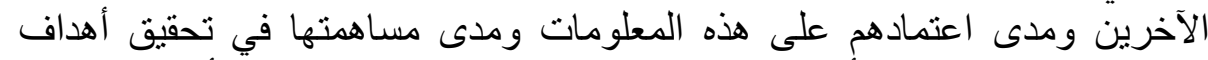

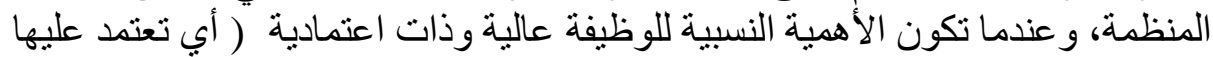

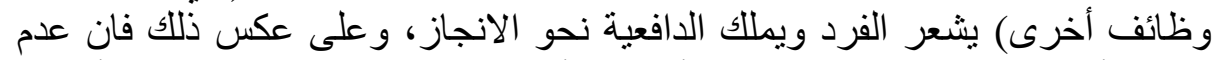

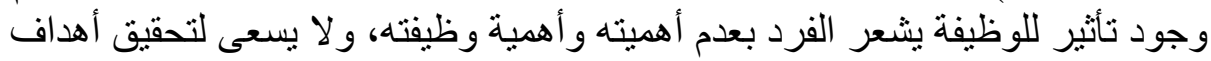

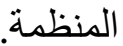

\section{سادسا: متطلبات التمكين ومعوقاته}

\section{1-منطلبات تمكين العاملين Workers Empowerment Requirements}

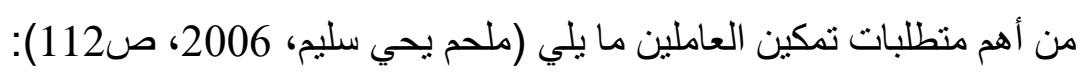

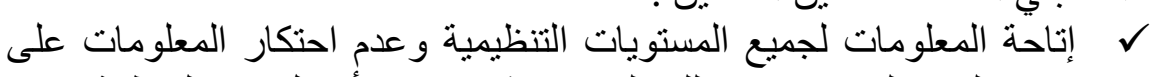

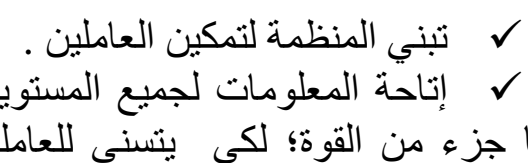

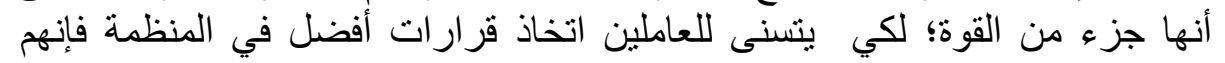

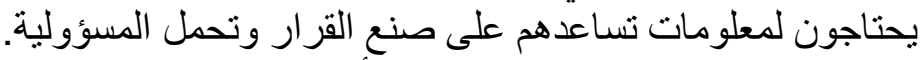

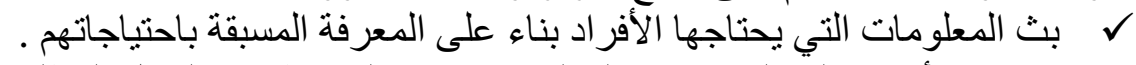

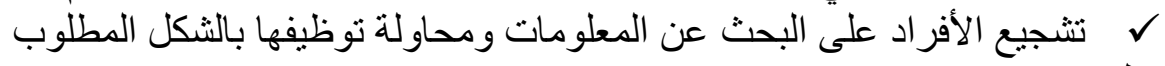


ل ل لشر المعلومات الخاصة بالأهداف و الخطط وتوضيحها للأفر اد العاملين .

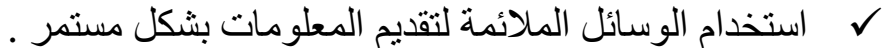

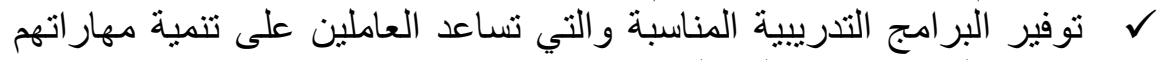
ومعارفهم ومحاولة تقوية نقاط القوة لديهم.

إضافة إلى ما ذكر يتطلب تطبيق تمكين العاملين التالي: (زكريا مطلل الدوري،

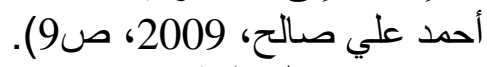

- صدث المنظمة وجديتها في منح الحرية للعاملين في المنظمة.

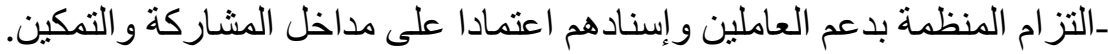
ـ نبذ الرقابة المباثرة وتعويضها بالرقابة الذاتية ضمن منظور الثقة المتبادلة بين

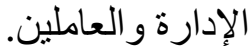

ـ اعتماد المنظمة التخطيط المنهجي عند تطبيق التمكين. ـ اللجوء إلى استخدام تقنيات منظمية مساعدة لتفعيل التمكين عن طريق فرق لتفين

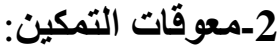

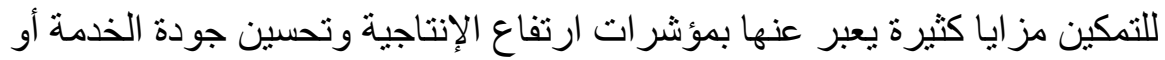

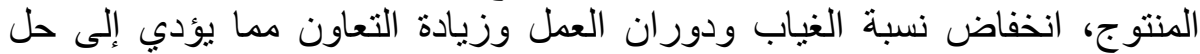

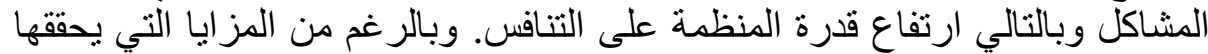

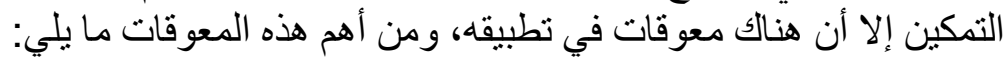
ـ ـ تمسك المدر اء بالصلاحيات و المسؤوليات.

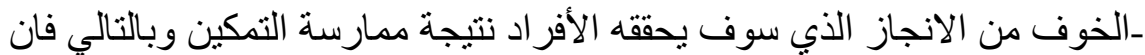
المدر اء الذين لا يملكون المهار ات و القدر ات الإبداعية يتأثر موقفهم ويشعرون بالضغط الضئ

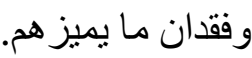
إضافة إلى المعوقات الذكورة يمكن أيضا ذكر ما يلي (خضير كاظم حمود، موسى

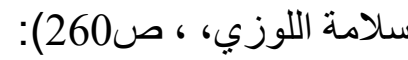

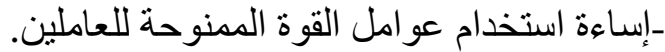

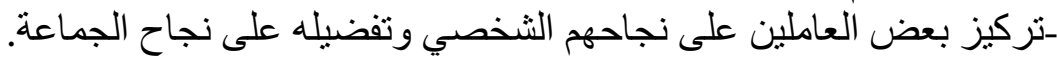

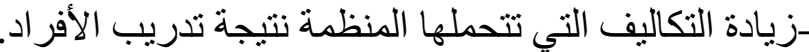
ـ-زيادة الوقت المطلوب لأداء العمل الجماعي و عمل اللجان.

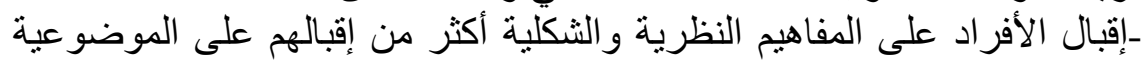

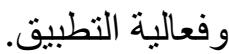
-زيادة الصر اع وتفتي الصر اع بين العاملين عند أداء العمل الجماعي.

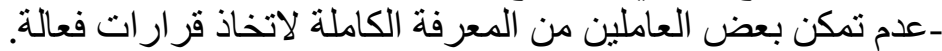

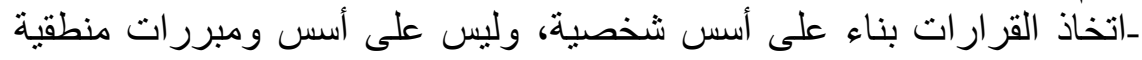


ومنه يمكن الاستتناج أن التغيرات الكثيرة والعديدة في البيئة الخارجية للمنظمة

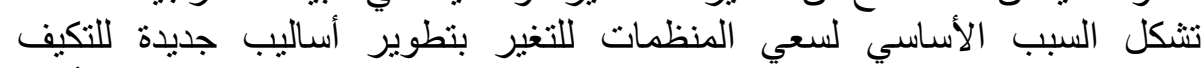

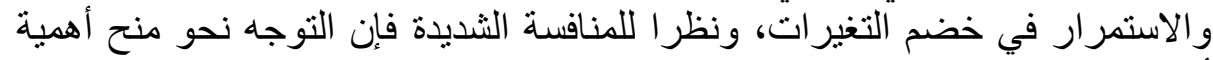

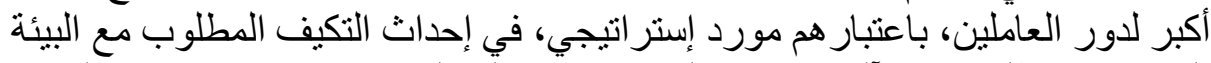

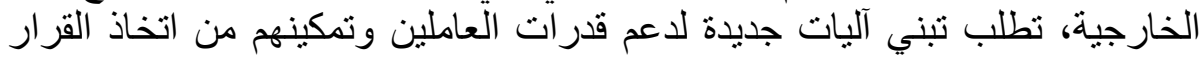

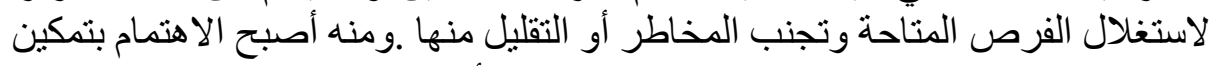

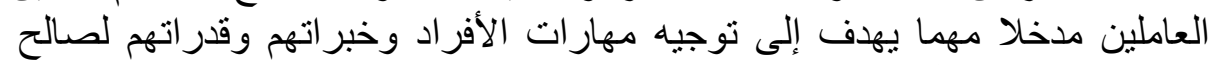
تحقيق إستر اتيجية المنظمة وتميز ها. المحور الثاني: رأس المال الفكري

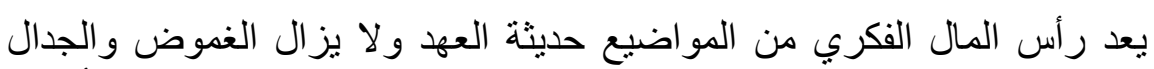

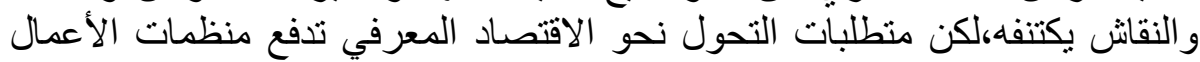

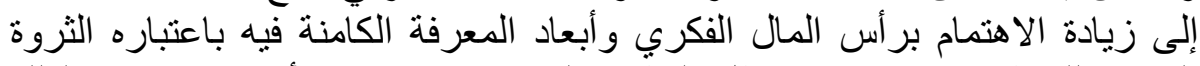

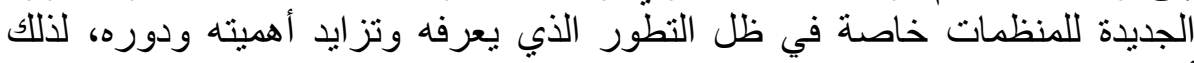

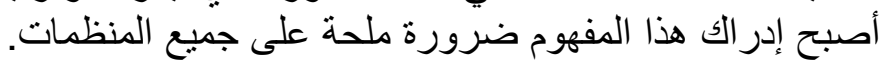

\section{أولا: مفهوم الرأسمال الفكري}

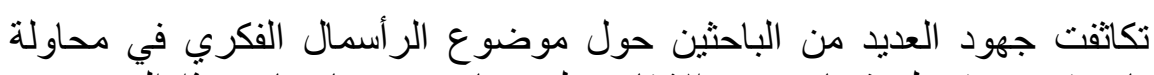

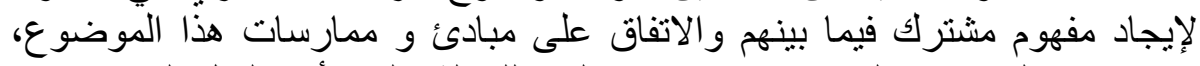

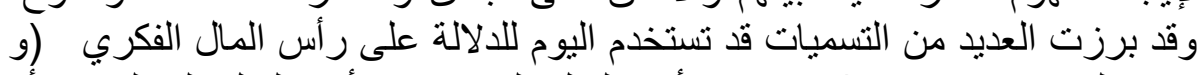

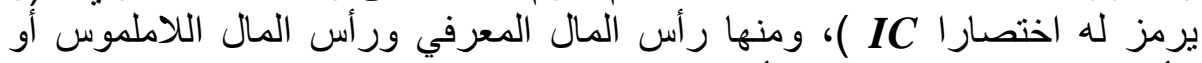
الأصول غير المادية فما هو رأس المال الفكري ؟ أس المال

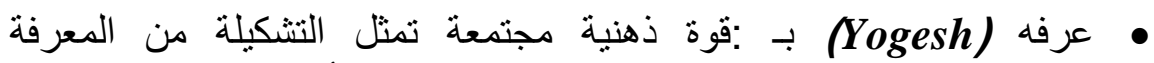

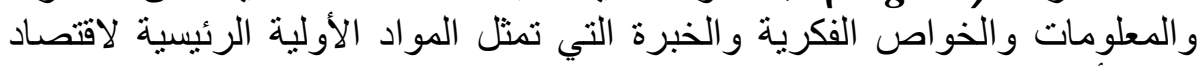

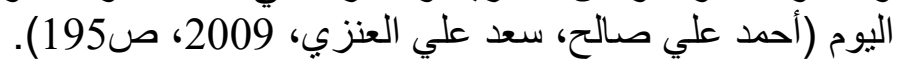

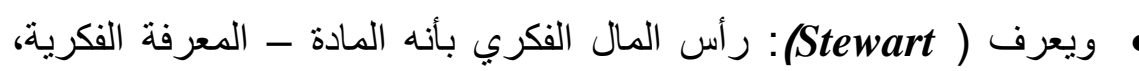

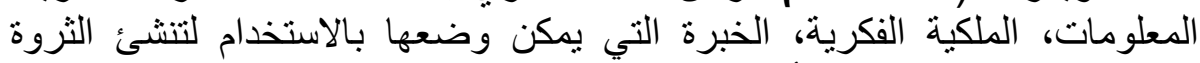

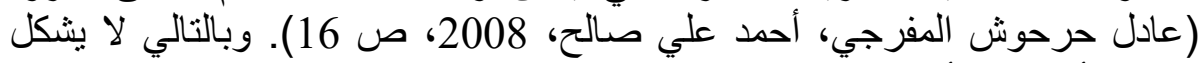

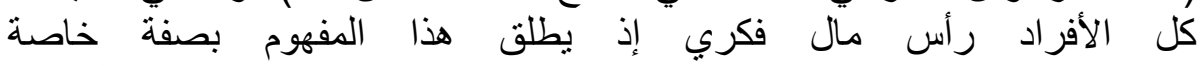

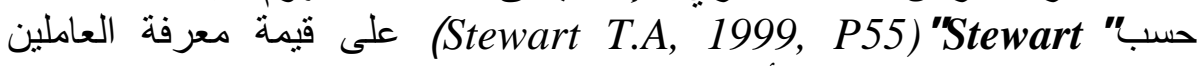
ومهار اتهم و معلوماتهم شرط أن تتصف بما يلي:

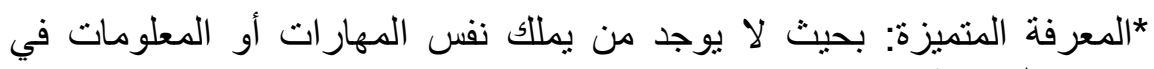
المؤسسات المنافسة. *المعرفة الإستراتيجية: أي أن تكون لتلك المهارات والمعلومات قيمة يمكن 
للزبون أن يدفع ثمنا مقابل الحصول عليها جر اء شرائه السلعة أو الخدمة المتميزة.

ر رأس المال الفكري هو القيمة الاقتصادية للأصول غير الملموسة ممثلة في القي

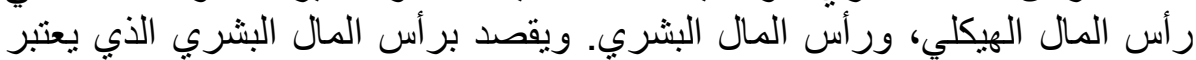

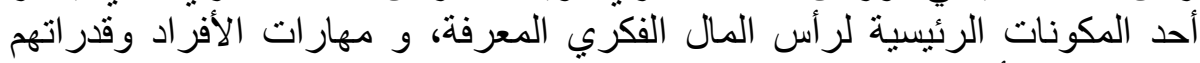

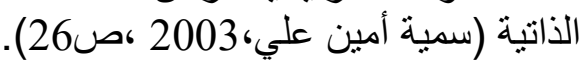

ويشير April الذي وضح حدودا فاصلة بين الموارد المادية والموارد

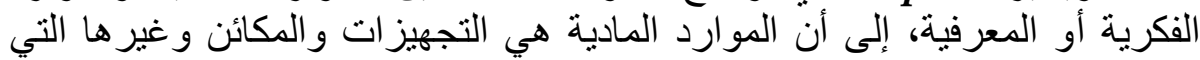

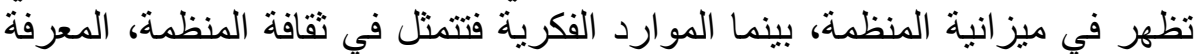

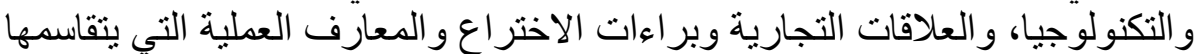

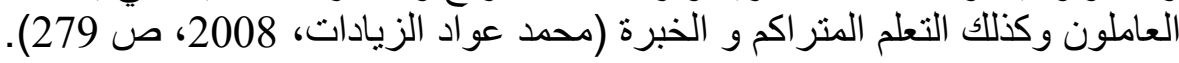

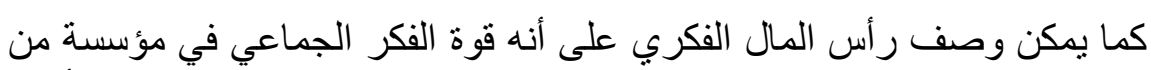

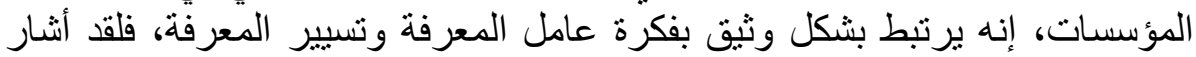

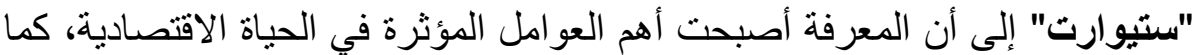

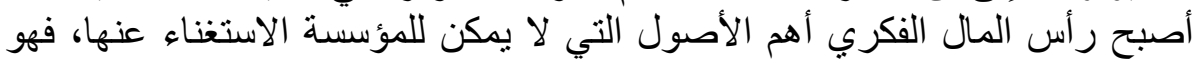

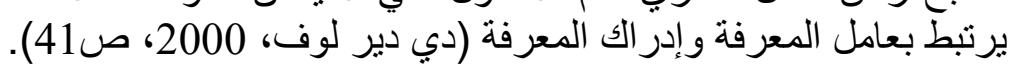

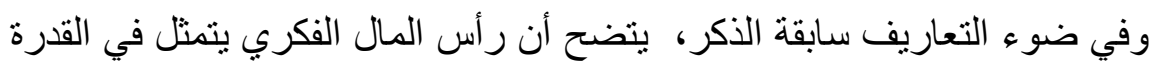

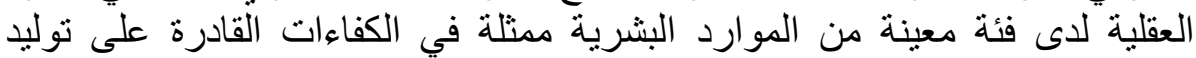

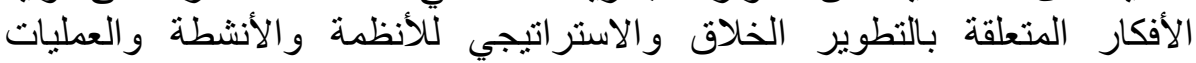
و الاستر اتيجيات بما يضمن للمؤسسة قيمة سوقية.

ثانيا: أبعاد تنمية رأس المال الفكري

أصبح رأس المال الفكري نقطة الارتكاز الأساسية لمنظمات الأعمال الجديدة

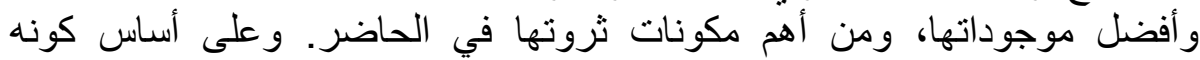

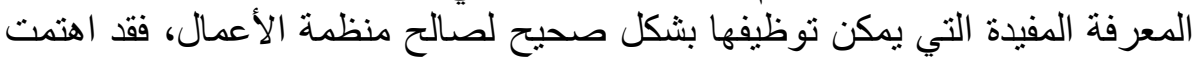

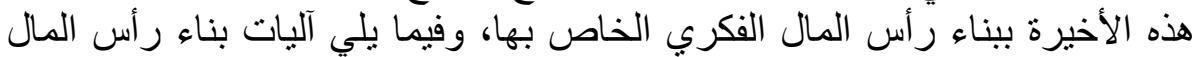

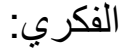

\section{1-استقطاب رأس المال الفكري:}

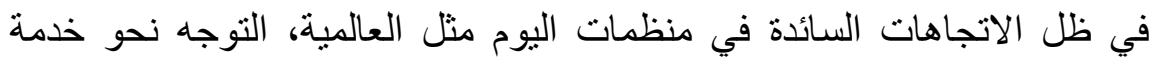
الزبون والتنافسية الثنديدة أصبحت المنظمات تولي أهمية كبيرة لاستقطاب المبت الموارد

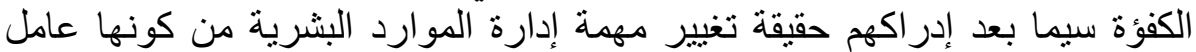

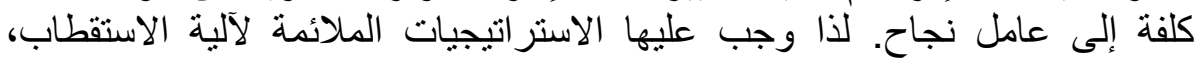
ومن أهم هذه الاستر اتيجيات نذكر (سعد علي العنزي, 2006, ص صاتئيات 264):

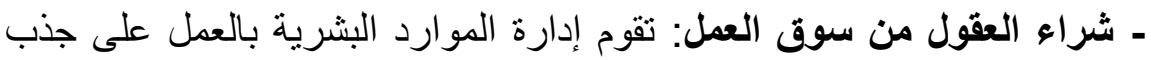


المهار ات و الخبرات المتقدمة والتي تستفيد منها المنظمة في زيادة رصيدها المياد المعرفي

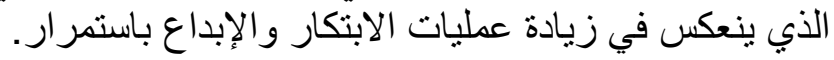

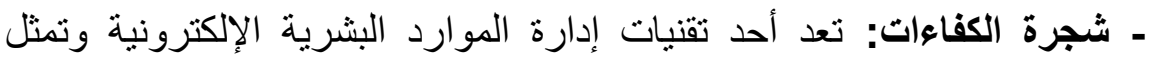

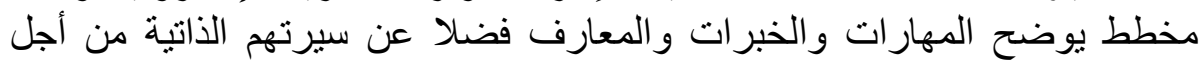

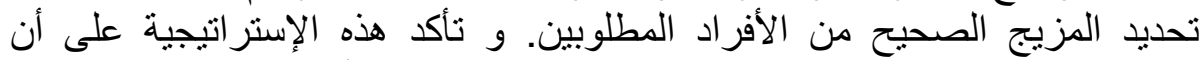

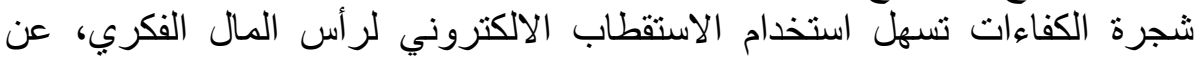
طريق شبكات الحواسيب (عبد الباري إبراهيم درة، زهير الإني نعيم الصباغ، 2010، ص440).

ـ مراجعة منظمات المعرفة والتعلم: تركز هذه الرؤية على أن المنظمات التعليمية

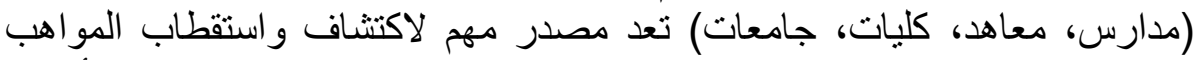

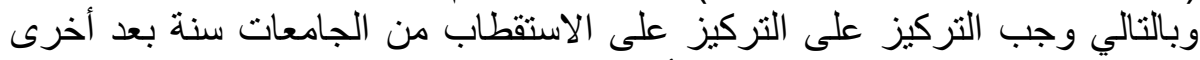
بدلا من الاكتفاء بالتعيين من شركات أخرى.

$$
\text { 2- صناعة رأس المال الفكري: }
$$

وتمثل صناعة رأس المال الفكري مصدرا للميزة التنظيمية وتر اكما لإمكانيات

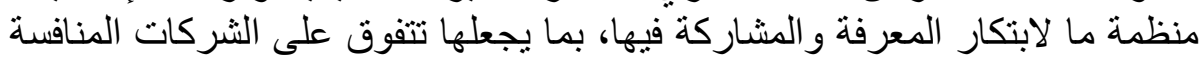

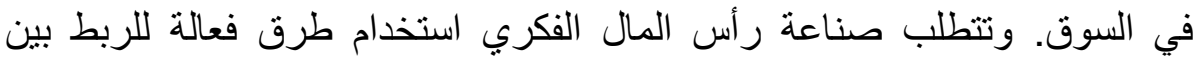

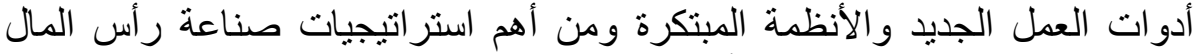

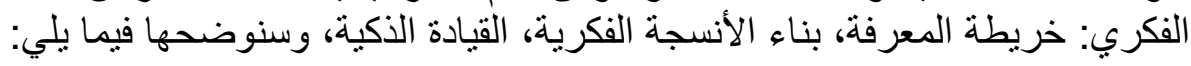
ـ خريطة المعرفة: وهي عبارة عن العرض المرئي للمعلومات التي يتم الحصول

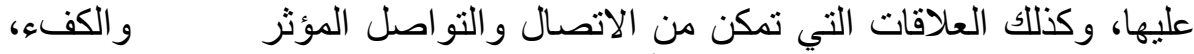

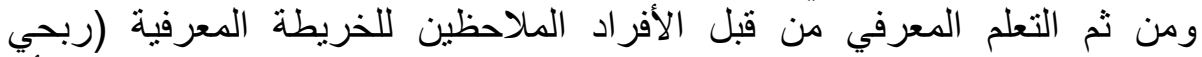

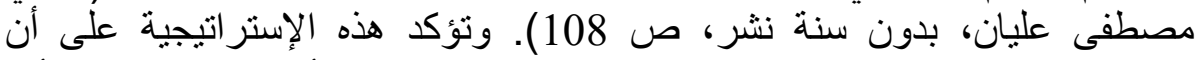

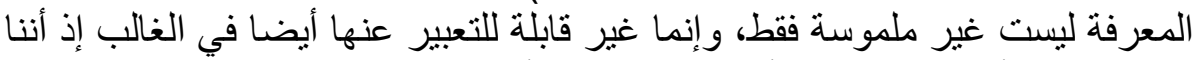

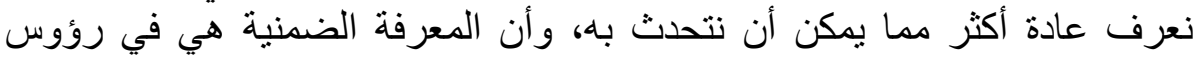

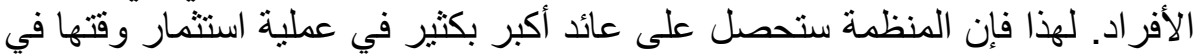

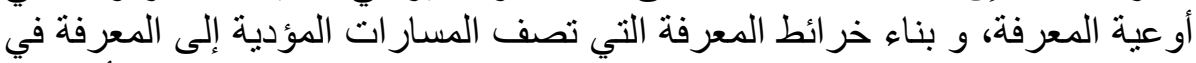

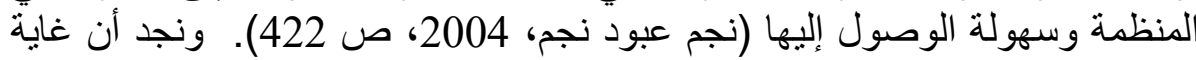
استخدام خريطة المعرفة تتمحور في: التئ

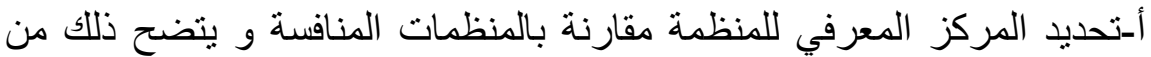

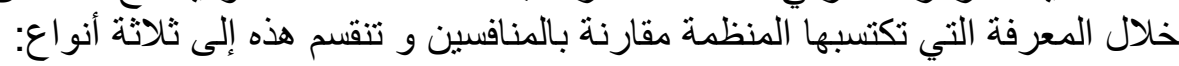

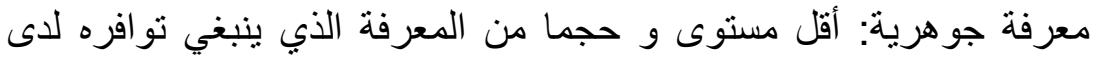

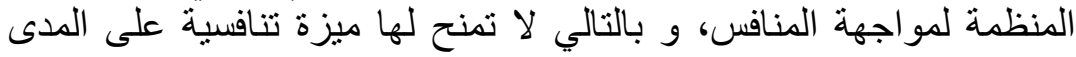

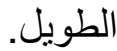


• معرفة متقدمة: و هي المعرفة التي تمكن المنظمة من اكتساب قدرات

المنافسة.

ه معرفة ابتكارية: وهي المعرفة التي تعطي المنظمة القدرة على القيادة و التمايز مقارنة مع المنافسين.

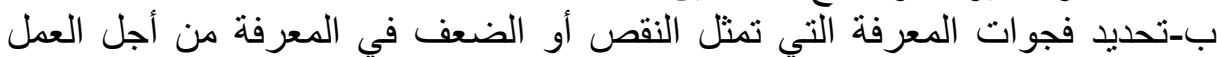

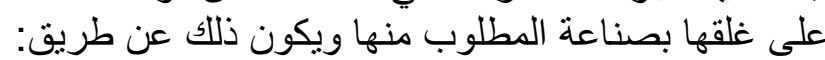
تعزيز قابليات الأفراد في مجال حل المشكلات بالاستفادة من المعرفة المدونة

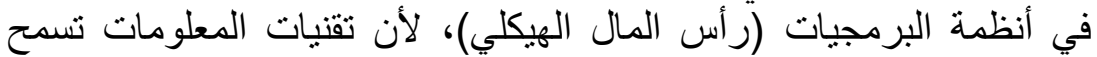

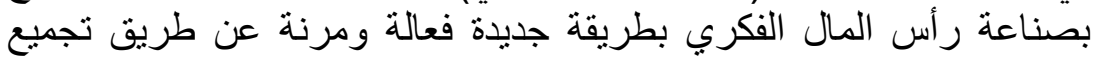

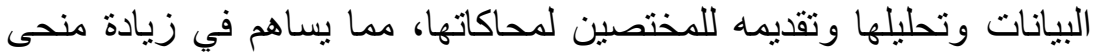

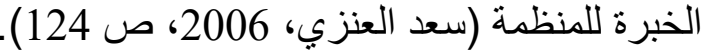

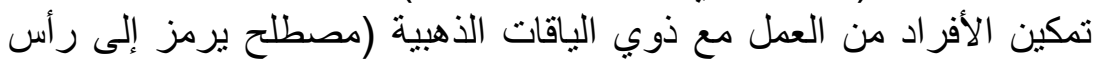

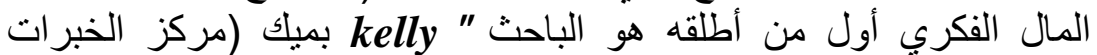

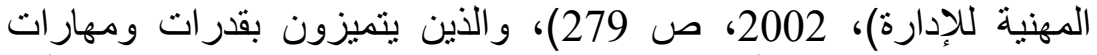

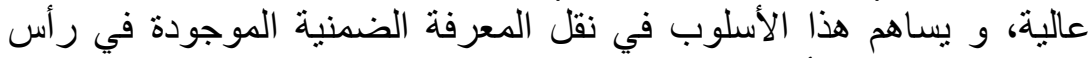

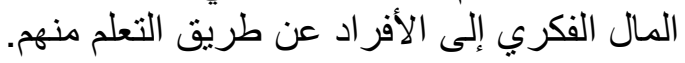

- بناء الأنسجة الفكرية: تمثل الأنسجة الفكرية تشكيل فرقي بشئ بشبه نسيج العنكبوت، يشارك فيه مجموعة ابتكارية تتفاعل وتتعلم من بعض ثخ ثم تنحل ليشكل

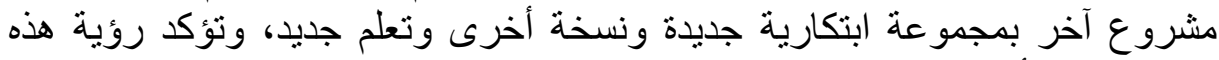

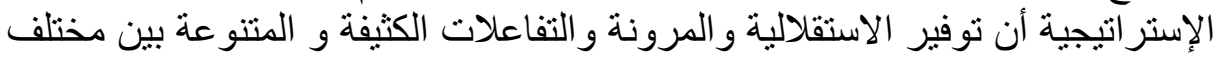

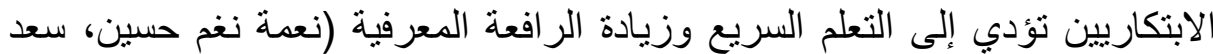

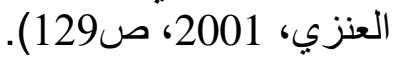

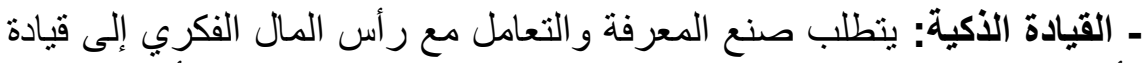

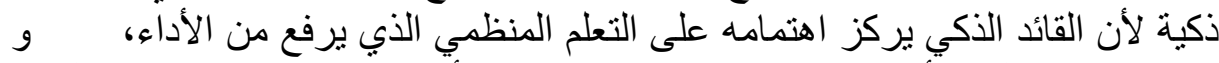

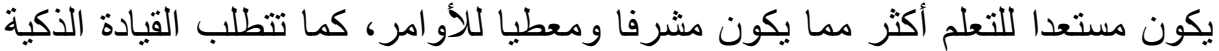
الاستمر ار و الفورية و الثنمول. ألثرئ.

بعد عرض آليات بناء رأس المال الفكري: الاستقطاب والصناعة، الصناء تجدر الإشارة إلى أن اختيار المنظمة للآلية المناسبة تحكمه جملة من المؤشرات النهات هي: الموازنة بين كلفة الاستقطاب أو /و الصناعة و العائد منها.

الموازنة بين تو افر القدرات العقلية داخليا و الحاجة إليها من خارج المنظمة. الموازنة بين الاستعداد لدخول أفراد جدد ومقارنة التغيير لر أس المال الفكري الموازنة بين الحاجة الدائمة لر أس المال الفكري و الحاجة المؤقتة له. 
إن مهمة المنظمة لا تقتصر فقط عل بناء رأس المال الفكري بل إنها تتوسع لتشمل

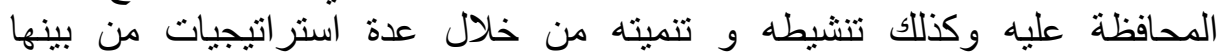

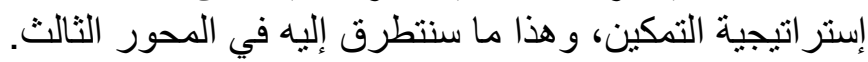

المحور الثالث: إستراتيجية التمكين و تنمية الرأسمال الفكري

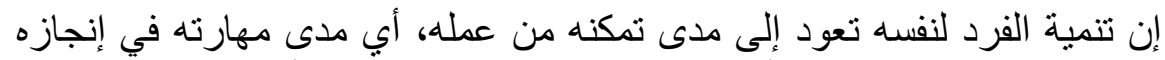

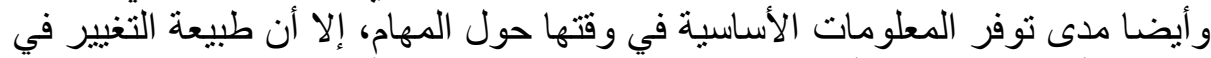

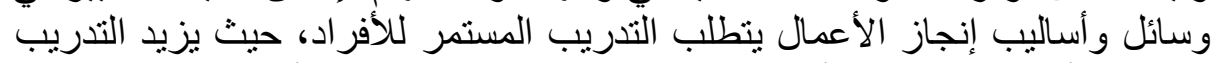

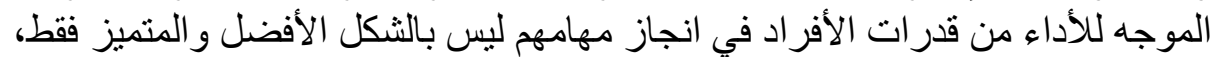

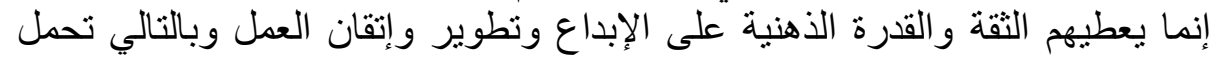

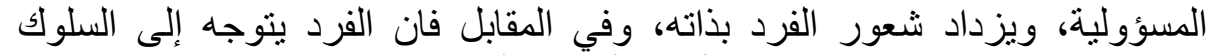

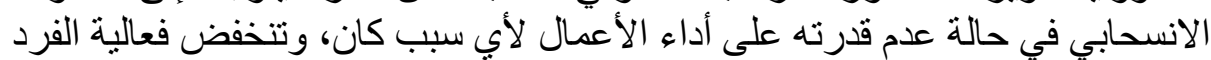

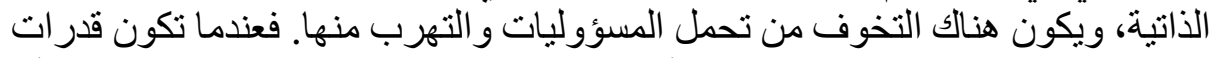

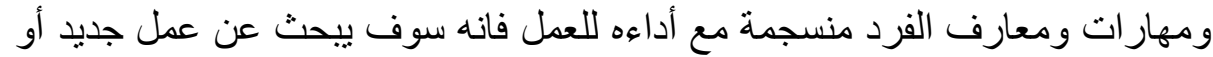

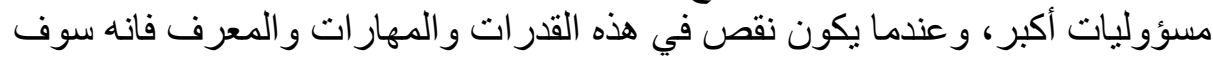

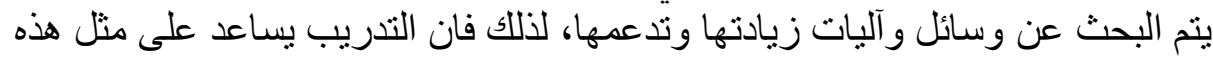

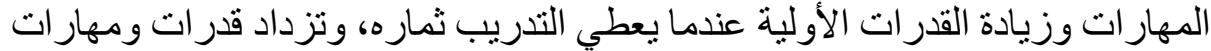

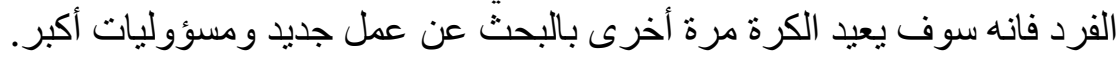
توجد علاقة قوية بين تحديد أهداف العمل والدافعية لانجاز العمل؛ فسلوك الفرد

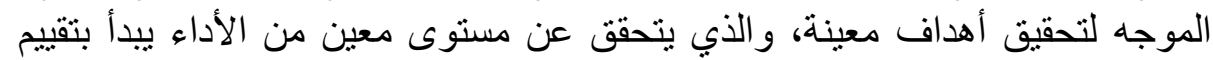

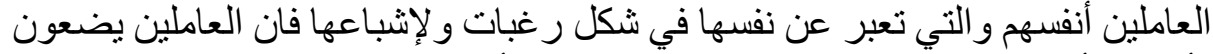

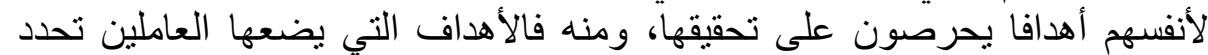
سلوكهم و أدائهخ.

ولألك فإن دور إستراتيجية تمكين العاملين في تتمية الموارد الرأسمال الفكري يتضح من خلال مجموعة من العناصر يمكن إظهار ها في ما يلي:

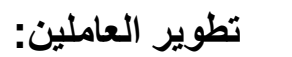

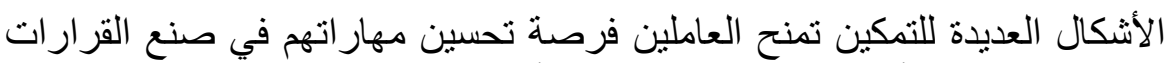

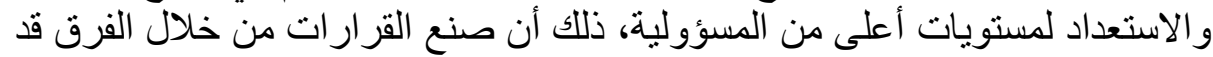

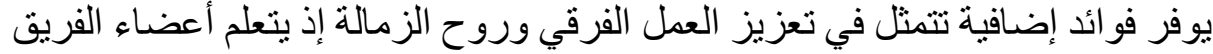

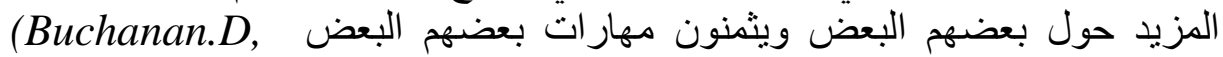
.Huczynski.A, 2004, P48)

\section{تمكين العاملين وشعور هم بالرضا:}

تدرك العديد من المنظمات بان تمكين العاملين غالبا ما يحسن شعور العاملين 
بالرضا و إحساسهم بالتمكين، إن التمكين يتصل بشعور الفرد بالسيطرة و الفاعلية الذاتية

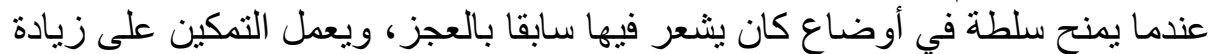

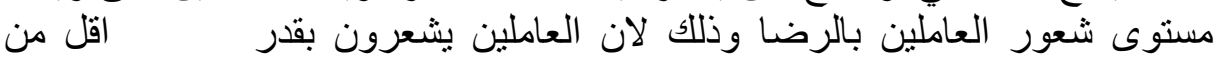

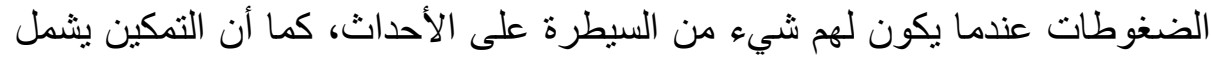

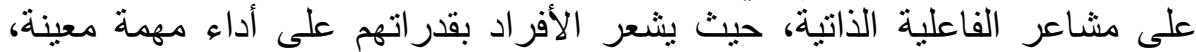

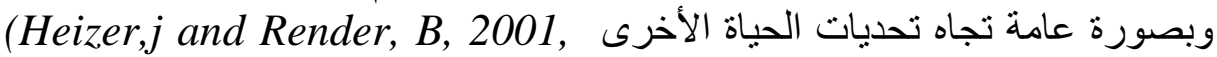

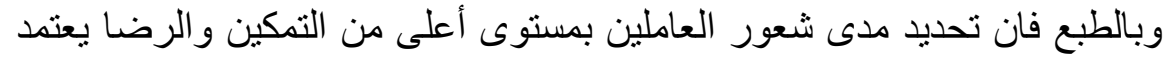

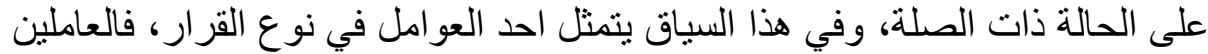

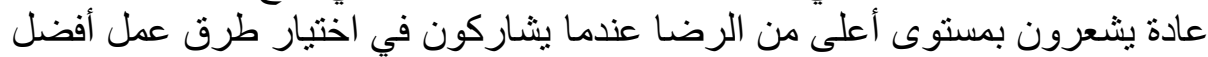

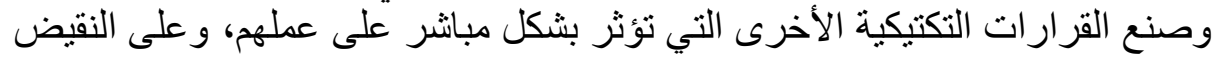

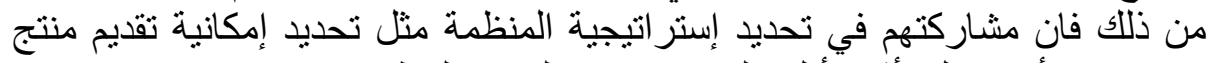

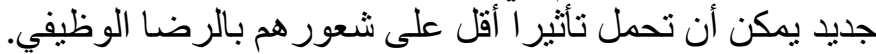

\section{جودة القرارات Decisions Quality}

السبب الأساسي الذي يدفع المنظمات إلى تشجيع تمكين العاملين هو أن التمكين

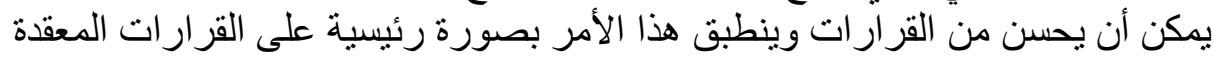

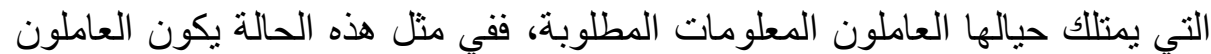

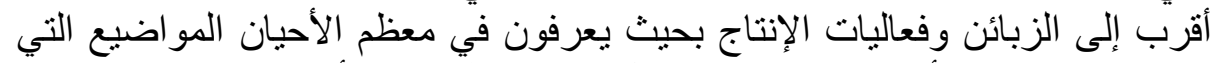

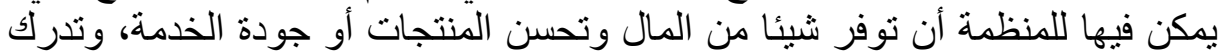

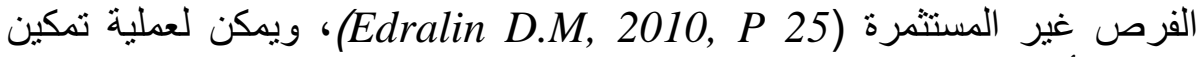
العاملين أن تحسن من جودة القرار ات بثلاث طرق و كما هو وارد في الثكل:

شكل رقم 01 :مساهمة تمكين العاملين في جودة القرارات

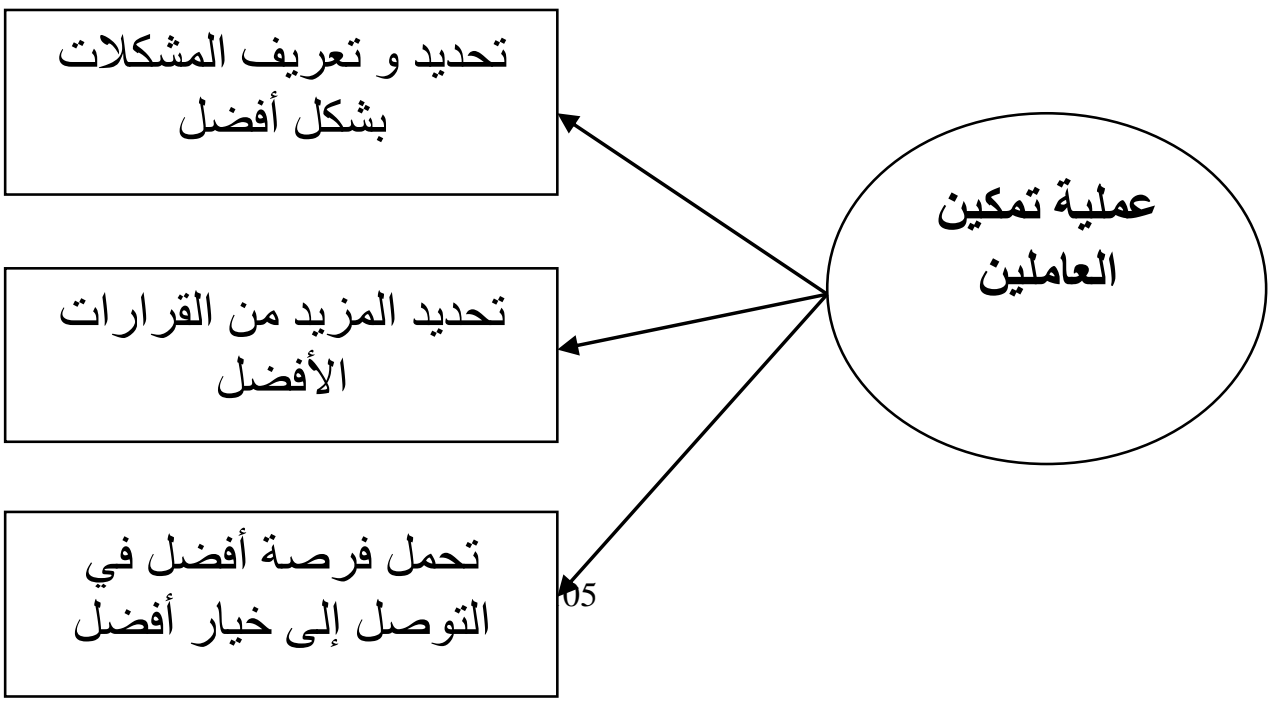


المصدر: (رامي جمال اندراوس، عادل سالم معايعة، 2008 ص147).

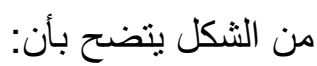

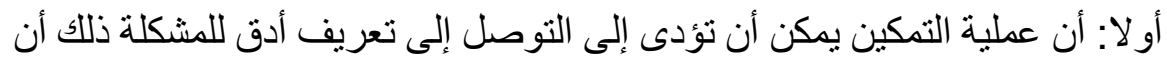

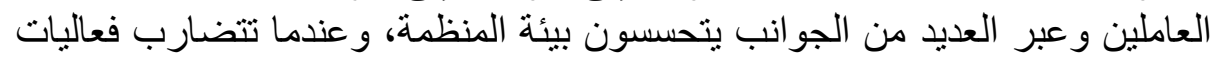

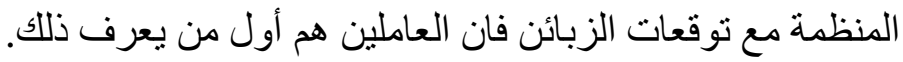

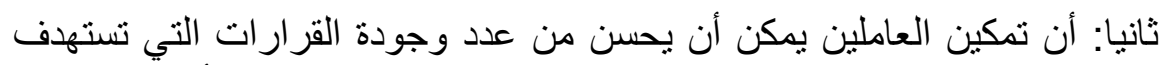

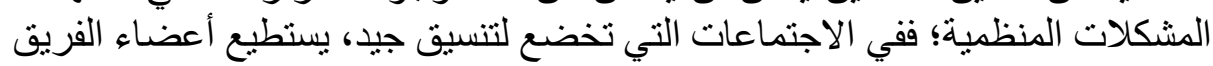

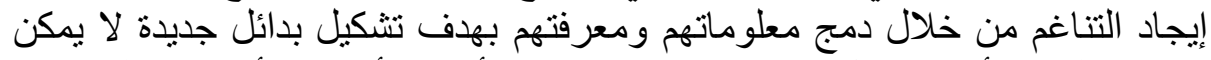

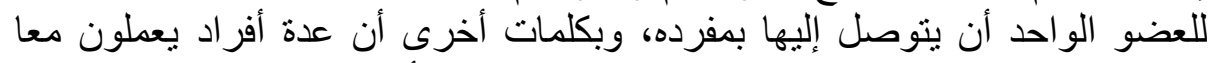

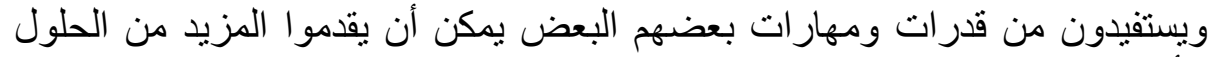
الأفضل التي لا يمكن التوصل إليها في حالة العمل الفردي.

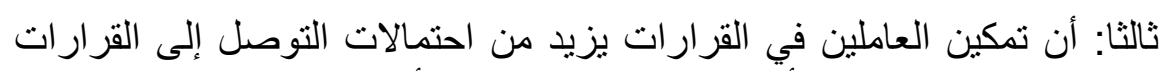

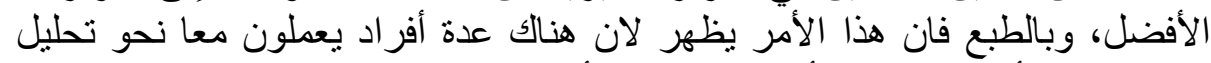
البدائل بشكل أدق عما يمكن أن يكون عليه الأمر في حالة العمل الفردي.

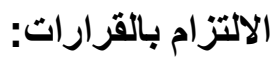

إن العاملين الذين يقومون بتنفيذ القرارات المنظمية يجب أن يكون لهم دور في لهي اختيار مسار التطبيق، أن هذا التمكين يوجد ملكية نفسية للقرار.

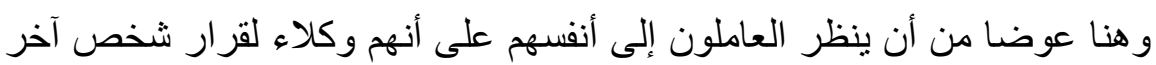

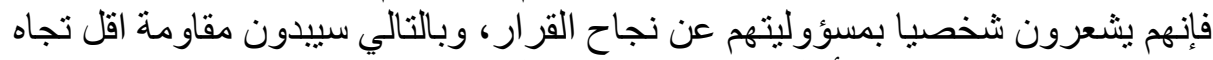
التغير وسيشعرون بدافعية أعلى نحو تطبيق تلات القرارات.

الخاتمة

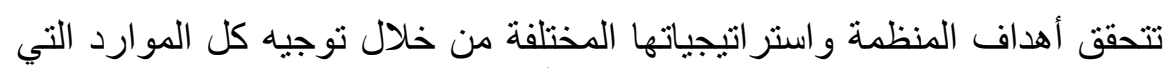

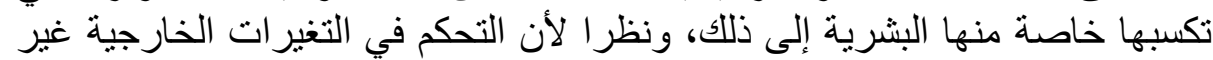

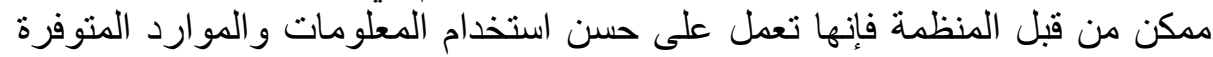

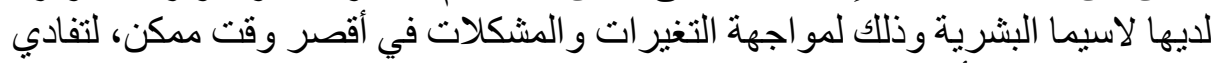
ضياع فرص و التأقلم مع التهيدات وتحقيق ميزة تنافسية للمنظمة. 
وتعد إدارة الموارد البشرية بمختلف استراتيجياتها الوسيلة الفعالة التي تستخدمها المنظمة للحصول على أفضل مورد بشري متاح في سوق العمل العل، التحسين المستمر في

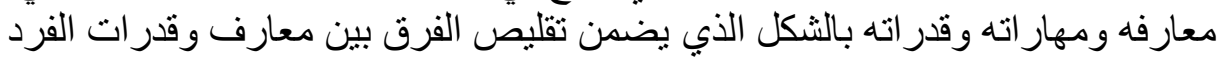

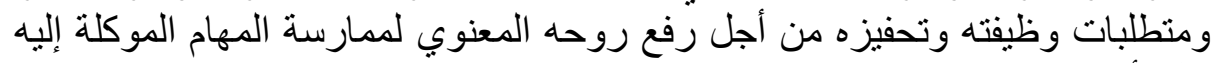

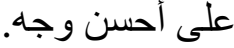

إن تمكين العاملين بالمنظمة بعتبر مطلبا مهما لتطوير طريقة تعامل موردها البشري

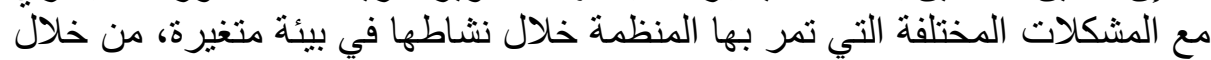

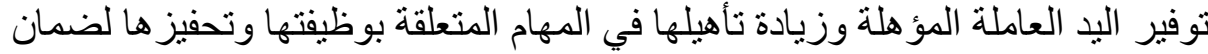
العطاء الدائم للمنظمة واستمر ارية ولاء لاء العاملين.

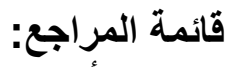

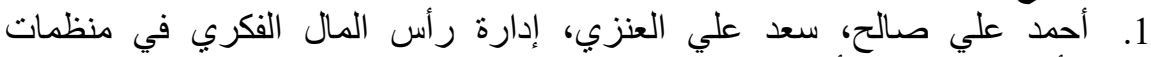
الأعمال، (عمان الأردن: اليازوري للنشر و التئي التوزيع، 2009).

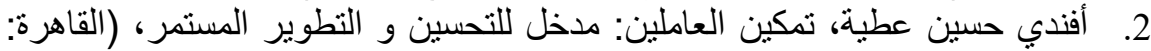
المنظمة العربية للتنمية الإدارية، 2003) العينة

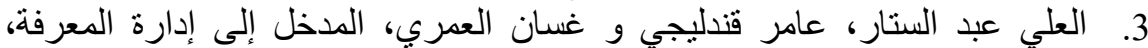
(عمان: دار المسيرة، 2006). 4. بلال خلف السكارنه، التطوير التنظيمي والإداري، (عمان: دار المسيرة للنشر و التوزيع و الطباعة ، 2009).

5. بيك (مركز الخبرات المهنية للإدارة)، الإدارة بذكاء: نتائج أفضل بموارد أقل،

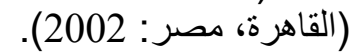
6. حسين حريم، مبادئ الإدارة الحديثة، النظريات، العمليات الإدارية، وظائف المنظمة،

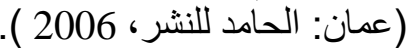
7. خضير كاظم حمود، موسى سلامة اللوزي، مبادئ إدارة الأعمال، (عمان: إثراء

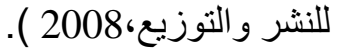
8. دي دير لوف، فكر رجال الأعمال: الطريق إلى النجاح المتكامل، (بيروت: دار

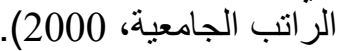

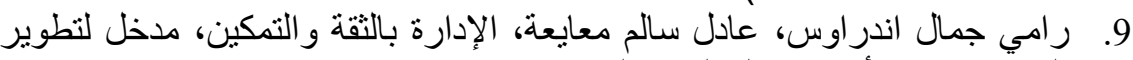

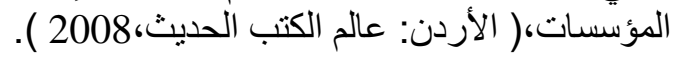

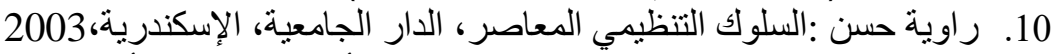
11. ربحي مصطفى عليان، إدارة المعرفة، الطبعة الأولى، (عمان، الأردن: دارئ، الإنة الصفاء

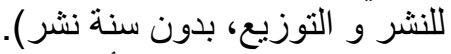

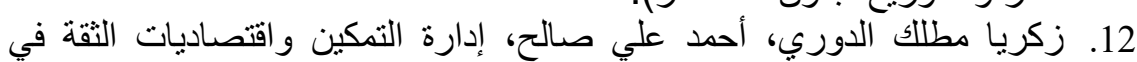
منظمات أعمال الألفية الثالثة، (عمان: دار اليازوري العلمية للنشر و التوزيع، 2009 13. زيد منير عبوي :الإدارة بالأهداف، الطبعة الأولى، (عمان: دار كنوز المعرفة للنشر 
14. سعد العنزي، فلسفة تحليل كلفة رأس المال البشري و استثماره، مجلة العلوم الاقتصادية و الإدارية، بغداد، 2006.

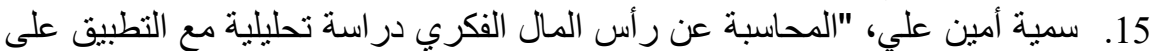

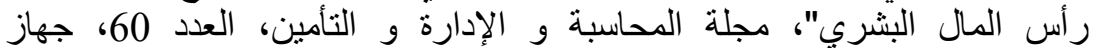

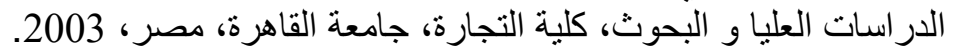

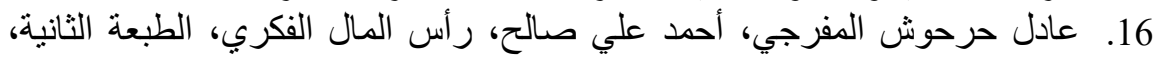

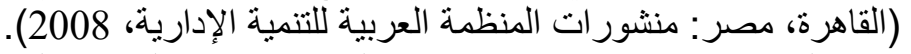

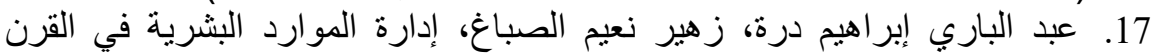

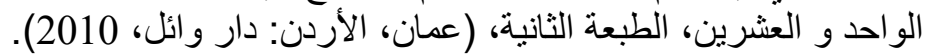

18. عبد الرزاق سالم الرحاحلة، نظرية المنظمة، (عمان: مكتبة المجتمع العربي للنشر

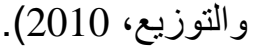

19. فايز جمعة صالح النجار ، عبد الستار محمد العلي :الريادة و إدارة الأعمال الصغيرة،

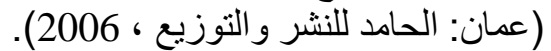

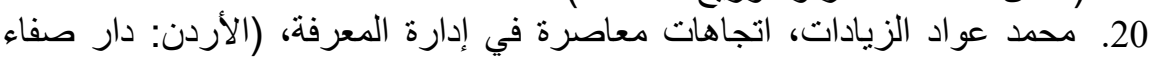
للنشر و التوزيع، 2008).

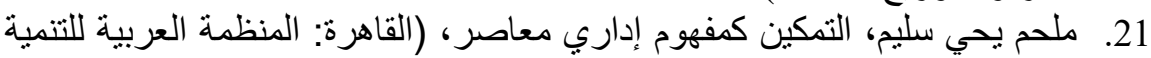

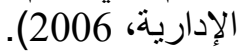

22. نبيل حامد مرسي صقر، التخطيط الاستراتيجي، (الإسكندرية: المكتب العربي الحديث، 2008).

23. نعمة عباس الخفاجي، طاهر محسن الغالبي، نظرية المنظمة مدخل التصميم، التوري،

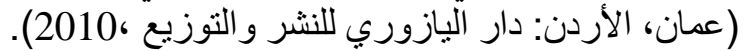

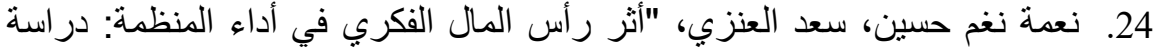

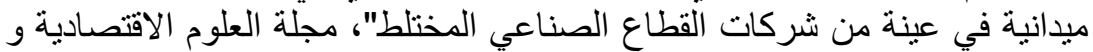
الإدارية، كلية الإدارة و الاقتصاد، جامعة بغدادّ، العدد 28، 2001.

1. Association of Business Executives, Human Resources Management,(United Kingdom:,William House, without edition year)

2. Buchanan.D, Huczynski.A, Organizational behavior : An introductory text, 5 th ed, (Prentice Hall, 2004).

3. Edralin D.M, Human Resource Management Practices : Drivers for simulating corporate entrepreneurship in large companies in the Philippines, DLSU Business and Economics Review, 19(2), 2010.

4. Jacques Castelnau et autres, Pilotage stratégique, 2 édition, (Paris: Edition d'organisations, 2001).

5. Heizer,j and Render, B, Opérations management, 6th ed, prentice Hall, 2001).

6. Stewart T.A, Intellectual capital: the new wealth of organizations, (New York: double Day-currency, 1999). 
